\title{
Magnetic Circuit Analysis and Fluid Flow Modelling of an MR Damper with Enhanced Magnetic Characteristics
}

DOI:

10.1109/TMAG.2020.3011669

\section{Document Version}

Accepted author manuscript

Link to publication record in Manchester Research Explorer

\section{Citation for published version (APA):}

Abdelmoneam Elsaady, W., Oyadiji, S. O., \& Nasser, A. (2020). Magnetic Circuit Analysis and Fluid Flow Modelling of an MR Damper with Enhanced Magnetic Characteristics. I E E E Transactions on Magnetics, 1-1. [10.1109/TMAG.2020.3011669]. https://doi.org/10.1109/TMAG.2020.3011669

\section{Published in:}

I E E E Transactions on Magnetics

\section{Citing this paper}

Please note that where the full-text provided on Manchester Research Explorer is the Author Accepted Manuscript or Proof version this may differ from the final Published version. If citing, it is advised that you check and use the publisher's definitive version.

\section{General rights}

Copyright and moral rights for the publications made accessible in the Research Explorer are retained by the authors and/or other copyright owners and it is a condition of accessing publications that users recognise and abide by the legal requirements associated with these rights.

\section{Takedown policy}

If you believe that this document breaches copyright please refer to the University of Manchester's Takedown Procedures [http://man.ac.uk/04Y6Bo] or contact uml.scholarlycommunications@manchester.ac.uk providing relevant details, so we can investigate your claim.

\section{OPEN ACCESS}




\title{
Magnetic Circuit Analysis and Fluid Flow Modelling of an MR Damper with Enhanced Magnetic Characteristics
}

\author{
Wael Elsaady ${ }^{1,2}$, S Olutunde Oyadiji $^{1}$, Adel Nasser $^{1}$ \\ ${ }^{1}$ School of Mechanical, Aerospace and Civil Engineering, The University of Manchester, M13 9PL, Manchester, UK \\ ${ }^{2}$ Mechanical Engineering Branch, Military Technical College, Cairo, Egypt
}

\begin{abstract}
A novel design of a magnetorheological (MR) damper is developed, fabricated, modelled and tested. The design includes some features that enhance the magnetic characteristics of the damper. The iron-cobalt-vanadium "Vacoflux-50" alloy and the "AMT-Smartec" MR fluid, whose magnetic characteristics have been predicted to enhance the performance of the damper, are employed in the new design. Moreover, the location of the MR fluid region in the piston construction has been chosen so that the magnetic field maximises.

To evaluate the impact of the proposed design improvements, an approach to modelling the performance of a previously-tested MR damper of a different design, different magnetic material, and different MR fluid has been developed. The approach combines a Finite Element Analysis (FEA) of the magnetic circuit, and a nonlinear analytical model of fluid flow. The results of the FE/analytical approach have been validated using the available published results of the same damper. Hence, the approach has been used to predict the performance of the same damper due to the employment of the proposed design improvements. The FE/analytical approach accounts for the nonlinear characteristics caused by the magnetic saturation of materials and the effects of fluid compressibility and aeration in the damper. It has been found that the implementation of the proposed design features leads to a remarkable increase in the magnetic field and the fluid yield stress. Also, the inclusion of the nonlinear magnetic and fluid flow characteristics have been found to affect the magnetic field distribution and the fluid yield stress greatly.
\end{abstract}

Index Terms - Bulk modulus, compressibility, finite element analysis, magnetic circuit analysis, magnetorheological damper, magnetorheological fluid.

\section{INTRODUCTION}

$\mathrm{M}$ AGNETORHEOLOGICAL (MR) fluids are smart materials, which are used in applications such as car shock absorbers [1-3], hydraulic valves [4], and journal bearings [5]. The massive increase of the viscosity of MR fluids in response to magnetic fields is the key factor of fluid smartness. Due to the magnetic characteristics of MR fluids, MR fluids manifest nonlinear behaviours in different applications, as the fluid is converted into a semi-solid state that has common properties of solids and non-Newtonian fluids under the effect of an external magnetic field [6]. The characteristics of magnetic materials are also nonlinear as they are affected by magnetic fields, which at extreme values result in magnetic saturation, and also manifest hysteresis when the magnetic field polarity is switched. This nonlinearity leads to additional difficulties in modelling and analysis of MR fluid devices.

MR fluids are composed of micro-sized ferromagnetic particles, suspended in a non-conductive fluid [6]. Additives in the form of stabilisers and surfactants are employed in most MR fluids to secure the suspension of relatively denser ferromagnetic particles in carrier fluids [7].

Under the effect of a magnetic field, the ferromagnetic particles queue in a network of rigid chains [8]. The network gives the MR fluid a considerable yield stress, $\tau_{y}$, which causes the fluid to exhibit viscous and plastic characteristics during flow [9]. Therefore, the flow behaviour of MR fluids is mainly a non-Newtonian magnetic-field-dependent flow behaviour. The flow behaviour is categorised into different modes depending on the MR application, namely flow (valve) mode, shear mode, and squeeze model [10]. MR dampers are generally operated in the flow mode. The magnetic response of the MR fluid depends on the type and concentration of ferromagnetic particles, applied current, and type of the magnetic material of the piston-cylinder configuration [11].

Different viscoplastic models were developed to investigate the behaviour of MR dampers under different load conditions. The models can be grouped under two main branches, namely quasi-static and dynamic models [12]. The difference between the two groups is the ability of dynamic models to predict the hysteretic behaviour of MR dampers, which the quasi-static models cannot. Hysteresis originates due to the energy required to dislocate the queued particle chains in the fluid in response to applied shear forces. Other sources of are also reported to cause the hysteretic behaviour of MR dampers such as fluid inertia, compressibility, and presence of air bubbles [13].

The quasi-static modelling of MR dampers can be performed by the analysis of the steady-state viscoplastic flow of MR fluids in annular ducts, which is basically a steady Poiseuille flow. The relation between the applied shear stress, $\tau$, and the fluid shear rate, $\dot{\gamma}$, is described based on one of the viscoplastic models. The most well-known viscoplastic models are the Bingham plastic model, Herschel-Bulkley model, and Casson model [14].

Dynamic models are categorised as parametric and nonparametric dynamic models. Parametric models generally represent the dynamic system of a damper by the arrangement of springs and dashpots [15]. Other parametric models are obtained from quasi-static models by the inclusion of extra terms to account for nonlinearity such as compressibility or magnetic hysteresis $[1,16]$. On the other hand, non-parametric models are obtained by experimental testing of MR dampers followed by the fitting of non-parametric models to the measured characteristics. In all cases, these parametric and non- 
parametric approaches are employed to account for the hysteretic behaviour of MR dampers [12, 17].

In this paper, a novel design of an MR piston is developed, modelled, fabricated and tested. The new design incorporates some characteristics employed to enhance the magnetic characteristics of the MR piston. To evaluate the impact of the proposed design characteristics, a previously-tested damper that was developed by Chooi [17] and Chooi and Oyadiji [1, 14, 18] has been modelled by a novel Finite Element Analysis (FEA) and an analytical approach. Hence, the effects of the implementation of the proposed design improvements in the previously-tested damper have been predicted by the results of the current approach, which has been validated via the available measurements published in $[1,17,18]$. The flow of magnetic field in the magnetic circuit of the damper has been modelled by FEA, whereas, an analytical dynamic model of the damper has been developed to investigate the dynamic characteristics of the damper based on modelling of the fluid flow.

The analytical dynamic model incorporates the same quasistatic analysis of the flow of MR fluid in annular ducts, presented in many studies [1, 12, 14, 17]. However, the dynamic model accounts for the effects of fluid compressibility and aeration of the fluid in the damper. Also, the current FE model accounts for the nonlinear magnetic properties of magnetic materials due to magnetic saturation.

The paper is organised as follows. The FE and the dynamic models of the previously-tested damper are presented in Section II, followed by the results of the models in Section III. Then, the design, FE modelling, and testing of the novel MR piston are presented in Section IV, where the enhanced magnetic features are shown. After that, the effects of the implementation of the enhanced magnetic characteristics in the previouslytested damper are predicted in Section V via the FE and the analytical models. Then, the effects of employing different magnetic materials are presented in Section VI. Finally, conclusions are drawn in Section VI.

\section{FEA AND THE ANALYTICAL MODELLING OF THE PREVIOUSLY-TESTED MR DAMPER}

\section{A. Construction of the previously-tested MR damper}

Schematic drawings of the MR damper developed in [1, 14, 17, 18] are shown in Fig. 1 and Fig. 2. The damper has the form of a piston-cylinder arrangement, as shown in Fig. 1. It consists of two chambers, namely the compression and rebound chambers. The compression chamber extends to a coaxial annular chamber which contains some trapped gas under certain pressure. The fluid flow is permitted between the chambers via the annular throttling area in the piston. The piston is composed of two concentric parts, as shown in Fig. 2. The two parts are made from a low carbon steel alloy and fixed together by plastic end caps such that the annular gap is produced. The inner part of the piston provides the housing for two coils connected in parallel. The ends of these coils come out of the piston rod to be connected to an electric power supply. The MR fluid employed in $[1,14,17,18]$ is a silicone-oil-based fluid, which was prepared using Carbonyl Iron Powders (CIPs). The main dimensions of the previously-tested MR damper are shown in Table 1.

\section{$B$. The FE modelling of the damper magnetic circuit}

A two-dimensional axisymmetric FE model of the magnetic circuit of the previously-tested MR piston, shown in Fig. 2, has been developed via COMSOL/Multi-physics. Thus, a steadystate solution of the magnetic field distribution has been determined. According to [19], the governing equations of the solver employed in COMSOL/Multi-physics are Maxwell's equation and Ampere's law, given, respectively, by:

$$
\begin{gathered}
\nabla \cdot \vec{J}=0, \\
\nabla \times \vec{H}=\vec{J},
\end{gathered}
$$

where $\vec{J}$ is the electric current density, $\vec{H}$ is the magnetic field intensity. The external contribution of the electromagnetic coil to the ambient current density is represented by:

$$
\vec{J}=\sigma \vec{E}+\overrightarrow{J_{e}},
$$

where $\sigma$ is the electrical conductivity, $\vec{E}$ is the generated electric field, and $\overrightarrow{J_{e}}$ is the eddy current density.

The magnetic flux density, $B$, in the MR fluid region is determined from the current FE model. Then, the available experimental data in [17] is used to determine the corresponding average yield stress of the MR fluid. In these experiments, the yield stress of the MR fluid was measured at different magnetic field densities using a parallel-plate rheometer. Thus, curve fitting was applied to the experimental measurements to draw the relation between the magnetic flux density, $B$, and the fluid yield stress, $\tau_{y}$, via a logarithmic equation as:

$$
\ln \left(\tau_{y}\right)=\left\{\begin{array}{cc}
1.88 \ln (B)+5.2 & \ln (B) \leq-0.3 \\
1.5 \ln (B)+5.1 & \ln (B)>-0.3
\end{array},\right.
$$

where, $\tau_{y}$ is expressed in $\mathrm{kPa}$, and $B$ is expressed in Tesla.

Thus, through the current FE model, the magnetic field density in the MR fluid region is determined and used to define the corresponding yield stress of the fluid.

\section{The quasi-static analysis of the fluid flow in the MR damper}

The quasi-static Poiseuille flow of the MR fluid in the annular throttling area of the previously-tested MR damper is analysed based on the Herschel-Bulkley model. The HerschelBulkley model imposes a non-linear function of the stress-strain relation, given as:

$$
\tau=\tau_{y}+\eta_{H B} \dot{\gamma}^{n},
$$

where $\eta_{H B}$ is the consistency index and $n$ is the flow index, $n<$ 1.

In the previous studies on the MR damper presented in [1, $14,17,18]$, it was shown that the Herschel-Bulkley model predicted the nonlinear characteristics of the fluid better than the Bingham plastic model. That was shown from the experimental measurements of the shear stress-shear rate diagrams of the MR fluid at different magnetic field densities. Hence, the model parameters, namely, the fluid yield stress and the consistency and flow indices were determined by curve fitting of the model function with the experimental shear stress- 
shear rate diagrams and used in the previous model. As the current study began with the analysis of the previous damper, the Herschel-Bulkley model, and the parameters used in the previous studies were adopted.

The quasi-static modelling of MR dampers adopts the following assumptions [1, 12, 14, 17]: (i) incompressible steady-state flow, (ii) laminar fully developed flow, (iii) axisymmetric flow with no swirl in polar coordinates, $u_{\theta}=0$, (iv) unidirectional flow in the direction of piston motion ( $x$ direction), $u_{r}=0$, where $u_{r}$ and $u_{\theta}$ are the radial and tangential components of fluid velocity, respectively. Also, (v) the pressure varies only with respect to $x$-direction, and (vi) the gravitational and inertial effects are neglected. Therefore, according to $[12,14]$, the quasi-static flow relation, $Q=f(\Delta p)$, can be written as:

$$
\begin{gathered}
Q=2 \pi\left[\int_{R_{1}}^{a} u_{1}(r) r d r+\int_{a}^{b} u_{p l u g} r d r+\right. \\
\left.\int_{b}^{R_{2}} u_{2}(r) r d r\right]
\end{gathered}
$$

where $a$ and $b$, are the extents of the plug region, $R_{1}$ and $R_{2}$, are, the inner and the outer radii of the throttling area, respectively. $u_{1}(r), u_{p l u g}$, and $u_{2}(r)$ are defined according to the Herschel-Bulkley model as:

$$
\begin{gathered}
u_{1}(r)=\left(\frac{1}{\eta_{H B}}\right)^{n} \int_{R_{1}}^{r}\left(\frac{d p}{d x} \frac{r}{2}-\frac{C_{1}}{r}-\tau_{Y}\right)^{n} d r \\
u_{2}(r)=\left(\frac{-1}{\eta_{H B}}\right)^{n} \int_{r}^{R_{2}}\left(-\frac{d p}{d x} \frac{r}{2}+\frac{C_{1}}{r}-\tau_{Y}\right)^{n} d r \\
u_{p l u g}=\frac{1}{\eta_{H B}} \int_{R_{1}}^{a}\left(\frac{d p}{d x} \frac{r}{2}-\frac{c_{1}}{r}-\tau_{Y}\right)^{n} d r \\
\Delta p=-\frac{d p}{d x} L \\
C_{1}=\frac{a b \tau_{y}}{b-a}=\frac{\Delta p a b}{2 L},
\end{gathered}
$$

Equations (6) to (11) are solved to determine the flow parameters of the current quasi-static model. To do so, a MATLAB script has been written, in which the fluid yield stress is defined according to the magnetic field density in the MR fluid region obtained from the current FEA. The model predicts the relation between the volumetric flow rate, and the pressure difference along the annulus, $Q=f(\Delta p)$, which is used subsequently to define the flow rate equation in the dynamic model.

\section{The overall dynamic model of the damper}

In this section, the dynamic model is illustrated. The results of the preceding quasi-static model are used in conjunction with the solution of the continuity equations of the fluid flow in the damper. The continuity equations of both chambers of the damper are determined based on Reynolds Transport Theorem by the assignment of each chamber as a control volume, as shown in Fig. 3. The general form of the continuity equation for a control volume can be written as [13]:

$$
\frac{d m_{\text {sys }}}{d t}=\frac{d}{d t} \oiiint \rho d V+(\rho A v)_{o u t}-(\rho A v)_{\text {in }}=0,
$$

where $\frac{d m_{s y s}}{d t}$ is the rate of change of the mass of the system, which has the value of zero, $\rho$ is the fluid density, $V$ is the control volume, and $(\rho A v)_{\text {out }}-(\rho A v)_{\text {in }}$ represents the net flux of mass through the control surface. Equation (12) can be written as:

$$
\oiiint \frac{d \rho / d t}{\rho} d V \pm Q \mp A \dot{x}=0,
$$

Substituting $\frac{d \rho}{d t}=\frac{d \rho}{d p} \cdot \frac{d p}{d t}=\frac{\rho}{K} \cdot \frac{d p}{d t}$, where $K=\rho \frac{d p}{d \rho}$ is the fluid bulk modulus, thus, the continuity equations of the chambers of the damper are written in the differential form as:

$$
\begin{gathered}
-Q+A_{1} \dot{x}=\left(\frac{V_{1 i}-A_{1} x}{K_{1}}\right) \frac{d p_{1}}{d t}, \\
Q-A_{2} \dot{x}=\left(\frac{V_{2 i}+A_{2} x}{K_{2}}\right) \frac{d p_{2}}{d t},
\end{gathered}
$$

where $A_{1}$ and $A_{2}$ are the corresponding piston area for each chamber, $V_{1 i}$ and $V_{2 i}$ are the initial volumes of fluid in each chamber, $x$ and $\dot{x}$ are the displacement and velocity of the piston, respectively, $p_{1}$ and $p_{2}$ are the pressures in the rebound and the compression chambers, respectively, and $K_{1}$ and $K_{2}$ are the bulk moduli of fluid in each chamber.

The advantage of performing this analysis based on the variation of the fluid bulk modulus is that the bulk modulus accounts for the effect of possible gas presence in the damper. Gas presence may be due to pre-charge, aeration, and cavitation in hydraulic cylinders. Aeration and cavitation in hydraulic cylinders are reported to affect the fluid bulk modulus greatly, especially at pressures lower than 100 bar $[13,20]$.

The gas content in the damper is represented by the existence of a gas pocket in the compression chamber, as shown in Fig. 1 , whereas the gas content in the rebound chamber is believed to be due to aeration caused by improper sealing due to the motion of the piston rod. Moreover, the dissolved air in the MR fluid contributes to the gas content. The variation of bulk modulus of the liquid-air mixture in each chamber can be written as [19]:

$$
\begin{aligned}
& K_{1}=\left(\frac{1}{K_{f}}+\frac{\varphi_{1}}{K_{\text {air }}}\right)^{-1}, \\
& K_{2}=\left(\frac{1}{K_{f}}+\frac{\varphi_{2}}{K_{\text {air }}}\right)^{-1},
\end{aligned}
$$

where $K_{f}$ and $K_{\text {air }}$ are the bulk moduli for the fluid and air, respectively, taken as $K_{f}=1 \mathrm{GPa}$ and $K_{\text {air }}=142 \mathrm{kPa}$. The bulk modulus of the fluid is estimated based on the information supplied by Dow Corning Corporation, which is the supplier of the silicone oil used [21].

The value of the bulk modulus is much higher in the rebound chamber, compared to that value in the compression chamber. This is due to the existence of a large gas pocket in the compression chamber, whose relative volume lowers the value of the bulk modulus significantly according to equation (17). The air content in the rebound chamber, which represents the dissolved air in the chamber, is assumed to have a constant volume fraction of $0.01 \%$ relative to the volume of the rebound chamber. This low volume fraction is assumed as the pressure in the rebound chamber is always higher than the atmospheric pressure due to the pre-charge pressure in the damper.

\section{E. Initial conditions and model parameters}

The piston displacement is assigned as a sinusoidal function, whose amplitude is taken as, $X_{a m p}=6 \mathrm{~mm}$ from peak to peak, while the frequency is taken as, $f=0.5 \mathrm{~Hz}$. The solution is initialised at the beginning of the compression stroke at zero 
piston velocity, and initial operating pressure of 5 bars. Thus, a complete cycle is fulfilled by the motion of the piston towards the compression chamber, then back to the rebound chamber.

In equations (14) and (15), $Q, p_{1}$, and $p_{2}$ are the unknown variables. Thus, equations (14) and (15) are solved with equation (6), obtained from the quasi-static analysis, to determine the three variables. To do so, another MATLAB code has been written in which the flow rate equation (6) has been defined in the code. Thus, the code solves the continuity equations and the equations of the bulk moduli described by equations (14) to (17) due to the sinusoidal motion of the piston. Then, the model predicts the damper force given by $[1,2,14$, 17, 18]:

$$
F=p_{1} A_{1}-p_{2} A_{2}+\text { fric. } \operatorname{sgn}(\dot{x})+m_{p} \ddot{x},
$$

where fric.sgn $(\dot{x})$ is the summation of all friction resistances multiplied by the velocity sign to interpret the direction as a resisting force, and $m_{p} \ddot{x}$ represents the inertial force of the piston.

\section{RESULTS AND DISCUSSIONS}

\section{A. Results of the FE model}

The contours of the magnetic flux density in the piston are shown in Fig. 4. The figure shows that the magnetic flux is denser in the coil core. Also, no magnetic flux is seen to flow in the piston rod, because it is made of a non-magnetic material. Moreover, the magnetic flux density in the MR fluid region, which has been used to define the fluid yield stress in the analytical model, is shown to be denser at the farthermost ends of the piston.

\section{1) Effect of direction of electric current}

Electric current is assumed to flow in both coils in the same direction. Therefore, the magnetic field mainly flows from the farthermost ends of the piston as shown in Fig. 2 and Fig. 4. This coil configuration, Configuration (A), is adopted, for example in [22]. However, it is different from the coil configuration presented in [16, 23], Configuration (B), in which the current in the coils flow in opposite direction. This causes the magnetic field to flow in the middle region of the piston, as shown in Fig. 5, which is better from magnetic saturation point of view. However, to achieve the same value of magnetic flux at all locations in (B) as in (A), it requires the piston to be operated at a higher electric current. In other words, this alternative configuration (B) leads to a better distribution of magnetic field in the MR fluid region at the expense of the value at the farthermost ends of the piston obtained in Configuration (A) shown in Fig. 2. Therefore, Configuration (B) is advantageous in terms of magnetic saturation problems as the magnetic flux is theoretically allowed to flow across the MR fluid region at four locations, rather than two locations in Configuration (A). However, a minimum value of the input current should be secured so that a reasonable magnetic effect is exhibited by the MR fluid. Configuration (B) is frequently adopted in multi-coil MR pistons, and it is also seen in a design of a single-coil MR piston developed recently by Idris et al. [24], in which they adopted a design of the piston that allows the magnetic flux to flow across the MR fluid region at four locations.
To investigate the effect of both coil configurations, the direction of the input current has been reversed in one of the coils in the FE model. The distribution of magnetic field density at the centre of the annular MR fluid region due to both configurations is shown in Fig. 6(a), whereas the contours of the magnetic flux density in the piston due to Configuration (B) are shown in Fig. 6(b). The figures indicate that the magnetic flux flows in the middle of the MR fluid region when the directions of input current in both coils are reversed, whereas the flow in the middle region is suppressed when the current has the same direction in both coils, which allows the flow of magnetic flux with a higher density at the farthermost ends of the piston. It was also found that Configuration (A) shown in Fig. 2 leads to a slight increase of around $2 \%$ in the average magnetic field in the MR fluid region. The results shown in Fig. 6 represent the magnetic field density at $I=1.0$ A. The same percentage increase was found at different input currents. Since the average magnetic field density is seen to be nearly the same in both coil configurations showing a slight increase due to the coil configuration shown in Fig. 2, the subsequent results in the paper are based on this coil configuration. In fact, it is hard to assess which coil configuration leads to a higher pressure difference of the fluid along the annulus, a shorter region that is highly-affected by magnetic field or a wider region affected by less magnetic field. This parameter requires further investigation, and it is more likely to be effectively investigated by coupled numerical techniques, in which the effect of inhomogeneous distribution of magnetic field on the fluid flow parameters can be investigated.

\section{B. Results of the quasi-static model}

The variation of the volumetric flow rate at different values of pressure difference along the annulus according to the quasistatic model is shown in Fig. 7. It is shown that a minimum pressure difference, $\Delta p_{\min }$ of 2.05 bars, is required to start the fluid flow in the throttling area of the MR damper due to the fluid yield stress. The velocity profiles of the MR fluid in the throttling area at different values of the pressure difference are shown in Fig. 8. The figure shows that the plug region becomes narrower at higher pressure differences.

\section{Results of the dynamic model}

The pressure in the rebound chamber predicted analytically using equations (5) to (17) is compared with the experimentally measured pressure in $[17,18]$, as shown in Fig. 9. The figure shows a close agreement between the predicted and the measured peak pressure values. The differences between the predicted and the measured results are thought to be due to the assumptions adopted in the analytical model. Also, the possible inflow and outflow of air to and from the rebound chamber during experiments due to improper sealing may cause some inaccuracies. The inflow and outflow of air are thought to shift the position of the maximum pressure points shown in the experiments. The points of the maximum pressure are theoretically located at the moments of maximum velocities of the sinusoidal motion of the piston, $(t=T / 4,3 T / 4)$, where $T$ is period of oscillation.

To describe the dynamic performance of an MR damper under sinusoidal excitations, two well-known curves, denoted 
as "work diagram" and "characteristic diagram", are used. The work diagram describes the variation of the damper force with piston displacement, $F-x$, whereas the characteristic diagram describes the variation of the damper force with piston velocity, $F-\dot{x}$. Both diagrams, which are obtained from the analytical model, are compared with the corresponding diagrams obtained from the experimental pressure curve in $[17,18]$, as shown in Fig. 10 and Fig. 11, respectively. A good agreement can be noted in both curves between the analytical and experimental results.

According to the characteristic diagram shown in Fig. 11, it is seen that the dynamic analytical model predicts the hysteric behaviour of the MR damper to an acceptable degree of accuracy, in comparison with the results deduced from the experimental pressure curve. The characteristic diagram according to the quasi-static model is also shown in the figure to assert the inability of quasi-static models to predict the hysteric behaviour of MR dampers. Therefore, it can be deduced that the hysteretic behaviour of the damper is mainly due to the compressibility of the MR fluid and the existence of air bubbles that have been accounted for in the dynamic model. The work diagrams at different amplitudes of the piston motion are shown in Fig. 12. The measurements at these amplitudes were not provided in the previous studies in $[1,14,17,18]$ under the same operating conditions of frequency and input current. However, the diagrams have similar profiles to those presented in many studies $[3,25,26]$.

\section{DeSIGN AND TESTING OF AN MR PISTON WITH ENHANCED CHARACTERISTICS}

A novel design of an MR piston has been developed, fabricated, modelled and tested. The design incorporates some design characteristics which were employed to enhance the magnetic characteristics of the piston. It will be used to develop a large-scale MR damper suitable for relatively higher loads. The magnetic circuit contains four electromagnetic coils, with a higher number of turns compared to the proposed design in $[1,14,17,18]$. The effects of the implementation of the suggested characteristics on the previously-tested damper in [1, $14,17,18]$ are predicted by the presented FE and analytical models in Section II.

The magnetic circuit of the new MR piston has been modelled by FEA following the same scenario presented in Section II-B. However, the effect of the nonlinear behaviour of magnetic materials has been included in the model. Moreover, the current FE model has been validated by the experimental measurements of the steady-state magnetic field density in the MR fluid region of the piston.

The objective of the suggested design characteristics in the new design is to maximise the magnetic field density in the MR fluid region. This ensures the energising of the damper with minimum electric power. Thus, the proposed modifications aim to enhance the magnetic characteristics of the piston by the variation of three design parameters, namely, the construction of the piston (location of the MR fluid region), the type of the magnetic material of the piston, and the type of the MR fluid.

The first modified feature in the new design is the construction of the piston. In common designs of MR pistons, the MR fluid region is located around the coil bobbin, as shown in Fig. 2, as can be seen in [3, 12, 17, 25, 26]. However, in the current design, the MR fluid region is located inside the bore of the coil bobbin. The reason for this suggested design is that the magnetic field is theoretically denser inside the coil bobbin. The motivation of this modification is the analysis of contours of magnetic field density presented in Fig. 4. The figure shows that the magnetic part of the piston below the coils is the region that is mostly affected by magnetic field. Therefore, the purpose of the insertion of the MR fluid region inside the coil bobbins is to bring the MR fluid region closer to that region. Therefore, the magnetic field will be slightly higher compared to the location of the region in the annular part around the coils. The higher magnetic field in an MR fluid region located inside the coil bobbin was seen in [26]. In that study, a different construction with both inner and outer MR fluid regions in the piston head was employed. The magnetic field density at the magnetic poles in the inner region was shown to be twice higher than that in the outer region. However, it should be noted that that high increase was achieved because the design presented in [26] employs two MR fluid regions. This means that the magnetic flux will be smaller in the outer region in comparison with common designs that employ a sole outer MR fluid region. Therefore, the employment of a sole inner MR fluid in this design may not achieve the same increase percentage of magnetic field.

The second design feature investigated is the selection of the piston magnetic material. The magnetic material employed in the current design is the iron-cobalt-vanadium alloy, Vacoflux50 , produced by Vacuumschmelze GmbH. This alloy is shown to have a very high relative permeability compared to ferritic and martensitic stainless steels, which are the common magnetic materials used with MR dampers [27, 28]. The detailed magnetic properties of this material are illustrated later in this section.

The third investigated design feature that leads to maximise the magnetic effect is the selection of the MR fluid. The characteristics of different types of MR fluids are investigated in terms of relative permeability and yield stress. Four MR fluids are compared, namely the AMT-Smartec ${ }^{+}$MR fluid produced by Arus MR Tech Company, MRF-140CG MR fluid produced by LORD Corporation, MRHCCS4-B MR fluid produced by Liquids Research Ltd., and the in-house produced MR fluid in $[1,14,17,18]$. The MR fluid employed in the current study is AMT-Smartec ${ }^{+}$MR fluid. The fluid is shown to have the best magnetic properties in terms of the yield stress and the relative permeability at low magnetic field strength.

\section{A. Design and fabrication of the novel MR piston}

The construction of the MR piston is shown in Fig. 13. The piston comprises four magnetic coils connected in parallel. The coils are enclosed by five magnetic spacers made of Vacoflux50. The coils are wound on non-magnetic bobbins made of nylon-66 and surrounded by isolators made of the same material. The coil assemblies and the magnetic spacers are fitted into an outer hollow cylinder made of Vacoflux-50. The magnetic spacers were press-fitted (interference fit) into the 
outer housing cylinder using a cold-press machine to reduce the losses of magnetic flux at the interfaces. A magnetic core made also of Vacoflux-50 is fitted on the aluminium piston rod to allow the flow of magnetic flux inside the coil bobbins where the MR fluid region is located. Thus, the MR fluid region is represented by the 3-mm wide annulus between the outer surface of the magnetic core and the bore of the magnetic spacers.

The piston is enclosed by two aluminium covers; each of them is provided with two openings, as shown in Fig. 14(a), to permit the flow of MR fluid. The magnetic spacers are provided with radial notches, as shown in Fig. 14(b), which are employed so that the free lengths of the wires at the ends of the coils pass through them, and through the holes provided in the right aluminium cover, out of the piston. Then, the free lengths of wires are fitted into the piston rod through two radial holes in the piston rod and they come out of the piston rod from an opening in its extreme end (not shown). The alignment of the coils and the spacers in the magnetic outer housing is shown in Fig. 14(c), which shows also the direction of coil windings.

The use of the nonmagnetic aluminium piston rod was mandatory in the current design, although it was expected to reduce the magnetic flux density in the MR fluid region. The reason for the use of aluminium is the insufficiency of the Vacoflux-50 material acquired to manufacture the piston as well as the piston rod. Also, there were limitations in the machining capabilities of the workshop where the components of the damper were manufactured. To allow fitting of the free lengths of wires, it was necessary to drill a very long axial hole through the centre of the piston rod. However, if the piston material is relatively hard, it was hard to drill the hole. Hence, an available hollow aluminium alloy tube of the right dimensions was used.

\section{B. Magnetic properties of Vacoflux-50}

Vacoflux-50 is an iron-cobalt-vanadium alloy produced by Vacuumschmelze GmbH, Germany. Iron-cobalt 50/50 alloys are high-permeability soft magnetic alloys that were invented in the United States since 1920 under the name of "Permendur" [29]. Then, similar alloys such as Permendur 2V and Supermendur were invented in which Vanadium was included as it led to improve machinability and mechanical properties of materials.

In comparison with different magnetic carbon steels, Vacoflux-50 shows a very high saturation limit of $2.35 \mathrm{~T}$, as can be shown from the $B-H$ curves of different magnetic carbon steel materials in comparison with Vacoflux-50 presented in Fig. 15 and Fig. 16. The data is adapted from the available information in [30-33]. The $B-H$ curve defines the relative permeability of material, $\mu_{r}$, according to magnetic flux density, $B$ and magnetic field strength, $H$, based on the following equation:

$$
B=\mu_{r} \mu_{0} H .
$$

where $\mu_{0}=4 \pi \times 10^{-7} \mathrm{H} / \mathrm{m}$, and it represents the permeability of vacuum.

The maximum values of relative permeability of different materials are shown in Fig. 17, whereas the field-dependent magnetic permeability of Vacoflux-50 is shown in Fig. 18. Both figures show that the value of the relative permeability of Vacoflux-50 is 7693 , which tends to the permeability of pure iron. Moreover, the effect of temperature on the relative permeability of Vacoflux-50 is reported to be minor [30]. The enhanced properties of Vacoflux-50 are also indicated by their low electrical resistivity, better machinability, and corrosion resistance [34].

Vacoflux-50 shows also better magnetic characteristics, even when compared with other iron-cobalt-vanadium alloys, as can be shown from Fig. 19. The figure shows the $B-H$ curve of Vacoflux-50 in comparison with other well-known iron-cobaltvanadium alloys. The data is adapted from [30, 33, 35]. The curves are plotted on a logarithmic scale of magnetic field strength, $H$, in order to show the variation of $B$ at very low values of $H$. It can be shown that Vacoflux-50 exhibits very good magnetic properties as it has a higher saturation limit compared to Vacoflux-17 and Vacoflux-18 HR. The figure also shows that the saturation limits of Permendur 2V and Vacoflux27 are slightly higher compared to Vacoflux-50. However, it is shown that the magnetic field densities of both alloys are low at low values of field strengths compared to Vacoflux-50. Supermendur is shown to have the best magnetic properties, especially at very low values of field strengths. However, it is thought that Supermendur is only available in the form of very thin strips. Therefore, Vacoflux-50 is thought to be the highest magnetic permeability material available in solid form. The employment of the materials shown in Fig. 16 and Fig. 19 in the current design is investigated later in Section VI based on the FE model presented.

Employment of Vacoflux-50 is not frequently reported in the literature with MR devices, compared to use of carbon steel alloys with different grades. An iron-cobalt-vanadium alloy was patented in [36] in order to be employed as a core of an MR piston. Macháček [28] used Vacoflux-50 to design an MR strut employed with a space launcher. Kubík [37] employed Vacoflux-27 and Vacoflux-18 HR to design an MR damper. However, the effect of the enhanced magnetic materials was not evaluated. Vacoflux-18 HR was employed to implement a nonlinear FE model of magnetic circuit of an MR piston presented in [38]. The model shows the effect of the nonlinear distribution of magnetic field density in the MR fluid region in the steady and harmonic-varying magnetic fields.

Vacoflux-50 was obtained from Vacuumschmelze $\mathrm{GmbH}$ in the form of short rods, from which the magnetic components of the piston were machined. Then, a heat treatment annealing process was applied on the final products to retain the magnetic properties. The annealing was performed by the company under pure dry hydrogen ovens. Hydrogen reduces material exposure to the atmosphere; therefore, it prevents oxidation, and also removes impurities in the material. The material was heated until $820^{\circ} \mathrm{C}$, then the temperature was held for 10 hours, and finally the cooling process was performed at the rate of 100 ${ }^{\circ} \mathrm{C} /$ hour to $300{ }^{\circ} \mathrm{C} /$ hour [34]. 


\section{Magnetic properties of AMT-Smartec ${ }^{+}$MR fluid}

The curves of $\tau_{y}-H, B-H$, and $\mu_{r}-H$ for the investigated MR fluids are plotted as shown in Fig. 20 to Fig. 22, respectively. Fig. 20 shows the fluid yield stress, $\tau_{y}$, against the magnetic field strength, $H$, as adapted from $[17,39,40]$. The figure shows that the AMT-Smartec ${ }^{+}$MR fluid has the highest yield stress at most magnetic field strengths, although the silicone oil-based MR fluid developed by Chooi [17] has a higher yield stress at higher magnetic field strengths. This shows the significance of the MR fluid developed by Chooi [17], as the fluid characteristics are comparable with those of other fluids developed by such well-known companies. However, MR dampers generally incorporate low magnetic fields [41]. Thus, higher yield stress at lower magnetic fields is thought to be preferable.

Fig. 21 shows the magnetic field density, $B$, against the magnetic field strength, $H$, as adapted from [39, 40, 42]. The $B$ - $H$ curve was not measured in Chooi's work [17]. The figure shows that the AMT-Smartec ${ }^{+}$MR fluid has also higher magnetic field density at low magnetic fields, compared to the other fluids, except at very low magnetic fields (approximately below 4000A/m), where the MRF-140CG MR fluid shows a higher magnetic field density.

Fig. 22 shows the relative permeability, $\mu_{r}$, against the magnetic field strength, $H$, as adapted from the $B-H$ curves presented in Fig. 21. The relative permeability has been determined by the determination of the gradient of the $B-H$ curves divided by permeability of vacuum, according to equation (19). The figure shows that the AMT-Smartec ${ }^{+}$MR fluid shows a high and consistent value of the relative permeability, compared to the other fluids, although the MRF140CG MR fluid shows higher relative permeability at very low magnetic field strength. However, the value decays rapidly at higher magnetic field strengths. The relative permeability was assumed as a constant value of 4 in [17], and it is usually assumed in the available literature as constant values between 3 and 10 [17, 43-45]. However, this assumption does not account for magnetic saturation of the fluid. It is worth noting that as some MR dampers operate under low magnetic field strength [41], therefore the MRF-140CG MR fluid may give better results in some constructions.

It should be also noted that the viscosity of the AMTSmartec $^{+}$MR fluid in the absence of magnetic field is considerably higher than that in the MRF-140CG MR and the in-house made MR fluid in [17]. The assessment of the fluid viscosity has been performed by the current authors by eye inspection of three samples of the fluids. The high viscosity of the fluid in the off-state may reduce the dynamic range in which MR damper are operated, especially because MR dampers are often employed with luxury cars as they conduce a better response to road conditions. That better response may not be achieved if the off-state viscosity of the MR fluid employed in the damper is high. Also, the high viscosity of MR fluids increase the possibility of the In-Use Thickening (IUT) problem, in which an MR fluid is transformed into a paste due to the long exposure of magnetic field [46]. It has been analysed that the AMT-Smartec ${ }^{+}$MR fluid has more iron particles than the MRF-140CG and the in-house made MR fluid in [17]. The use of the AMT-Smartec ${ }^{+}$MR fluid is thought to be not reported in the literature, as the producing company of the fluid is recently established since 2015 . A similar fluid produced by the same company was reported to be used in the purpose of MRfluid-based finishing process to enhance material surface roughness [47].

\section{Modelling and simulation of the developed magnetic circuit}

The magnetic circuit analysis of the novel MR piston has been performed by a steady state FEA, using the AC/DC module in COMSOL/Multi-physics, following the same modelling strategy presented in Section II-B for the previouslytested damper in $[17,18]$. To account for the effect of nonlinear magnetic behaviour in the current FE model, the magnetic properties of materials have been defined by the inclusion of the corresponding $B-H$ curves.

The investigated computational domain is the whole piston head, including the aluminium covers, as shown in Fig. 23. The reason for the inclusion of the aluminium covers in the computational domain is to depict the decay of the magnetic field density in the MR fluid regions adjacent to the aluminium covers. The magnetic properties of Vacoflux-50 are defined according to the built-in library nonlinear magnetic materials in COMSOL/Multi-physics [33]. The $B-H$ curve is based on experimental measurements performed by Vacuumschmelze $\mathrm{GmbH}$ and provided to the authors [30, 33, 48], and it also matches the built-in $B-H$ curve defined in COMSOL/Multiphysics [33]. Similarly, the relative permeability of the AMTSmartec $^{+}$MR fluid is defined in COMSOL/Multi-physics according to the $B-H$ curve shown in Fig. 21. The parameters of the FE model are defined in Table 2.

The governing equations are the same shown by (1) to (3), presented in Section II-B. The coils are defined to be parallel connected in COMSOL/Multi-physics. Magnetic insulation is assumed at the boundaries of the FE domain. An FE mesh using triangular elements has been established with a total number of 25,233 elements, which includes 2012 edge elements, and 70 vertex elements. The mesh is extremely refined in the MR fluid region as shown in Fig. 23. A grid-independent solution has been achieved.

\section{E. Results of the FE model of the new design}

The steady state magnetic field parameters in the MR piston have been determined by the current FE simulation. The magnetic field densities in the centre of the annular MR fluid region at different input currents are plotted as shown in Fig. 24. It is shown that the magnetic field density increases at the MR fluid regions adjacent to the farthermost Vacoflux-50 spacers. However, the magnetic field density is less at the regions adjacent to the intermediate spacers. This is because that the thickness of the intermediate Vacoflux-50 spacers is smaller than the farthermost ones. The magnetic field is further decreased in the MR fluid regions adjacent to the coils. The figure also shows the construction of the MR piston and the 
effect of magnetic saturation on the distribution of magnetic field density with the increase of input current. It is seen that the magnetic flux density at the inner Vacoflux-50 spacers reduces due to the effect of magnetic saturation. The distribution of the steady-state magnetic field strength along the MR fluid region with the input current is shown in Fig. 25.

The variation of the distribution of the magnetic field density in the radial direction across the MR fluid region was found to be negligible, as shown by the surface plots in Fig. 26, except for very small areas of the fluid at the corners of the coils where the magnetic flux is concentrated. Thus, the assessment of the magnetic field distribution in the MR fluid region at the centre of the annular fluid region is an acceptable simplification, as also reported in $[23,26]$.

\section{F. Experimental measurements and validation of the current FE model}

The magnetic field density in the current MR piston was measured at different locations in order to validate the FE model. The steady-state measurements have been performed using a magnetic field meter, model Extech-MF100, which employs a Hall-effect sensor and a temperature compensation unit. The magnetic field meter has a built-in microprocessor which processes the signal of the Hall-effect sensor and shows it digitally on an LCD screen. The setup of the experiment is shown by the well-labelled photograph in Fig. 27. The magnetic field meter and the MR piston are fixed on a vertical holder with the aid of a counterweight and a wooden block. The piston has been located in a manner that the Hall-effect probe can be traversed to different vertical locations relative to the piston through the MR fluid region. The magnetic circuit of the MR piston has been energised using an electric power supply with DC. At each vertical location of the sensor, the corresponding magnetic field indicated on the magnetic meter was recorded. Thus, the steady state magnetic field density has been recorded at different locations and different input currents to the coils.

The measurements cannot be performed while the MR fluid exists in the MR piston, as also reported in [49]. The reason is that the relative permeability of the MR fluid is higher than that of the Hall-effect sensor. Thus, the magnetic flux will flow around the sensor instead of flow through the sensor. Generally, Hall-effect sensors are suitable for magnetic measurements in air and water, as the values of the relative permeability of both materials are $\mu_{r}=1$, which is the same as the material of the Hall-effect sensor.

In order to validate the current FE model, the MR fluid in the MR piston was replaced by air in the current measurements and also in the FE modelling. Hence, the experimental measurements of the steady state magnetic field density, at different locations and input currents, were compared with the theoretical magnetic field density, obtained from the FE solver, as shown in Fig. 28. The lower magnetic field density due to the replacement of the MR fluid by air can be seen by comparing Fig. 24 and Fig. 28. In Fig. 24, which involves the MR fluid, the maximum flux density is about $0.83 \mathrm{~T}$. However, in Fig. 28, in which the MR fluid was replaced by air, the maximum flux density is only about $0.12 \mathrm{~T}$. Also, the directly proportional increase of the magnetic field density with the applied current can be noted in Fig. 28, unlike the nonlinear increase shown in Fig. 24. That is due to the effect of magnetic saturation in Fig. 24, which involves the MR fluid. It is also shown in Fig. 28 that the maximum magnetic field density increases mainly at the regions adjacent to the Vacoflux-50 spacers.

\section{PREDICTIONS OF THE EFFECTS OF THE ENHANCED} MAGNETIC CHARACTERISTICS IN THE TRADITIONAL MR PISTON

The impacts of the implementation of the suggested design modifications and the new magnetic materials in the previously-tested MR piston developed in [1, 14, 17] have been investigated by the models presented in the current paper. The effects of employing the Vacoflux-50 and the AMT-Smartec ${ }^{+}$ MR fluid have been investigated by updating the material properties and the inclusion of the nonlinear magnetic properties in the FE model developed in Section II-B. Moreover, to evaluate the effect of the insertion of the MR fluid region inside the coil bobbin rather than being around the bobbin, a minor modification to the MR piston has been proposed. The effect of each of the design and material changes has been evaluated solely based on the nonlinear FE model, as presented in Sections V-A to V-C. Then, the combined effect of all the improved parameters is presented in Section V-D based on the nonlinear FE and the analytical dynamic models. The results are investigated at the input current of $I=1(\mathrm{~A})$. However, the results obtained at different currents are presented and compared to their counterparts of the original design as shown in Table 3.

\section{A. Effect of changing the magnetic material}

The effect of changing the magnetic material of the developed MR piston in [1, 14, 17] with the Vacoflux-50 is investigated. The magnetic material used in $[1,14,17]$ was magnetic stainless steel, in which the relative permeability was assumed to have a constant value of 2000 [16]. The distribution of the magnetic field density along the MR fluid region of the previously-tested MR piston for both design configurations is shown in Fig. 29. It is shown that the magnetic field density is increased at the locations of the extreme ends of the piston by approximately $17.8 \%$, compared to the corresponding value in the traditional construction. However, the difference is negligible in the intermediate region. This leads to an increase of the fluid yield stress at the extreme locations of the piston by $36.1 \%$. The average magnetic field in the MR fluid region is increased by $16.8 \%$ in the new configuration, according to equation (4). Table 3 shows that the percentage of the increase of magnetic field density at the locations of piston shoulder are around the value of $17 \%$, except for at $I=2.0$ A where the value is shown to be $7.6 \%$. That reduction in the gain is due to magnetic saturation which is accounted for in the current nonlinear FE model, whereas it was neglected in the model developed for the original design. It is worth to say that the percentage increase in the magnetic field in this investigation is higher than the $10 \%$ increase achieved in [36], in which an iron-cobalt-vanadium alloy was employed as a core of an MR piston. 


\section{B. Effect of changing the MR fluid}

The effect of replacing the MR fluid used in $[1,14,17]$ with the AMT-Smartec ${ }^{+}$MR fluid is investigated. The $B-H$ curve of the AMT-Smartec ${ }^{+}$MR fluid, shown in Fig. 21, was defined in the current FE model, and the steady state magnetic field distribution has been determined. The significant increase of the magnetic field density in the MR fluid region due to the employing of the AMT-Smartec ${ }^{+}$MR fluid is shown in Fig. 30. It is shown that the magnetic field density increases by about $160 \%$ at the extreme ends of the piston, and the average magnetic field in the MR fluid region is increased by $155 \%$. This increase leads to the increasing of fluid yield stress at the extreme ends of the piston by $490 \%$. The yield stress of the AMT-Smartec ${ }^{+}$MR fluid is obtained according to the available information in the fluid data sheet [40], by substitution with magnetic field strength. Indeed, this massive increase in the magnetic field density at lower magnetic fields is due to both the higher relative permeability and the fluid yield stress of the AMT-Smartec ${ }^{+}$MR fluid compared to the in-house produced MR fluid in $[1,14,17,18]$, as discussed in Section IV-C. The fluid yield stress is shown to be increased with different percentages according to the input current, as shown in Table 3. It is shown that the yield stress increases by $1035 \%$ at $I=0.5$ A, $297 \%$ at $I=1.5 \mathrm{~A}$, and $200 \%$ at $I=2.0 \mathrm{~A}$.

\section{Effect of employing the MR fluid region inside the coil bobbin}

The effect of employing the MR fluid region inside the coil bobbin is investigated by implementing a minor modification in the MR piston design shown in Fig. 2. The location of the MR fluid region has been changed to be inside the coil bobbin, as shown in Fig. 31. Thus, the MR piston comprises two parts as proposed in [1, 14, 17]. However, the coils are assembled in the outer part instead of the inner part. In addition, the same thickness of the aluminium core employed in $[1,14,17]$ has been employed in the model. Therefore, the inner part of the piston comprises the aluminium core and the magnetic stainless steel core. If the whole core is made of magnetic material, that will lead to a higher magnetic field density. However, the modified construction has been assumed in that way in order to solely investigate the effect of the insertion of MR fluid region inside the coil bobbins. All the main dimensions of the piston have the same values as in $[1,14,17]$, namely the outer radius, the widths of the magnetic poles, the dimensions of the coils, and the total length of the piston.

The effect of modifying the MR piston design by the suggested scenario on the magnetic field density is shown in Fig. 31. The modification has been predicted to lead to a minor increase in the magnetic field compared to the original design in $[1,14,17]$. The magnetic field density is predicted to increase at the extreme ends of the piston by $2.8 \%$ compared to the original design. Therefore, the corresponding increase in the MR fluid yield stress at shoulders locations is shown to be 5.3 $\%$ according to equation (4). The average magnetic field in the MR fluid region is predicted to increase by around $12 \%$. The little gain in magnetic field compared to the design presented in [26] is due to the different constructions of both pistons. In [26], the damper has two MR fluid regions; one is located inside the coil bobbin, whereas the other is around the coils. The variations of parameters at different input currents are shown in Table 4.

\section{Combined effect of all design and material changes}

The effect of combining all the preceding design improvement and material changes, namely Vacoflux-50, AMT-Smartec ${ }^{+}$MR fluid, and the insertion of the MR fluid region inside the coil bobbin on the increase of magnetic field in the MR region of the damper developed in $[1,14,17]$ is shown in Fig. 32. It is seen that the magnetic field density increases by $220 \%$, at the locations of the extreme ends of the piston, which leads to a corresponding increase in the fluid yield stress, $\tau_{y}$, by $634 \%$ relative to the original design in $[1,14,17]$. The average magnetic field in the MR fluid region, $B$, is increased by $247 \%$ in the new configuration.

The variations of parameters at different input currents are shown in Table 4. The table shows that the increase in the magnetic field and the fluid yield stress due to combining all the design enhancements and material changes is less than those increases due to the employment of the AMT-Smartec ${ }^{+}$MR fluid only at input currents $I=1.5 \mathrm{~A}$ and $I=2.0 \mathrm{~A}$. This is because that the model developed for the investigation of the employment of the AMT-Smartec ${ }^{+}$MR fluid only assumes a constant magnetic permeability of steel whose value was defined as 2000 according to [17]. On the other hand, the model developed for the investigation of the effect of the combined parameters is nonlinear, in which the magnetic permeability is defined according to the $B-H$ curves of materials. This indicates the importance of considering the nonlinear material properties in the model, as it can be deduced that the model results may be overestimated, especially at high input currents, when constant values of magnetic permeability are used.

It can be deduced that the massive increase of parameters compared to the original design is mainly due to the high magnetic permeability and yield stress of the AMT-Smartec ${ }^{+}$ MR fluid. The fluid characteristics exhibit very high yield stress at very low magnetic fields, as shown in Fig. 20, which may be useful in different MR applications such as MR gun recoil dampers. However, it may be also a limitation in some other devices where a low yield stress and a low fluid viscosity are required at low magnetic fields, whereas a relatively higher yield stress is required at higher magnetic fields.

Moreover, the effect of combining all the preceding parameters that led to maximise the magnetic effect on the performance of the MR damper presented in $[1,14,17]$ is investigated by the current analytical dynamic model, as shown in Fig. 33 and Fig. 34. Fig. 33 shows the work diagram which depicts the increase of the damper force against piston displacement due to the implementation of the suggested design and material changes, whereas Fig. 34 shows the characteristic diagrams. The same excitation frequency and operating current employed in [1, 14, 17] were employed in the current investigation. Both diagrams show an increase in the maximum force of the damper by around $550 \%$ in the enhanced design relative to the corresponding value of the original design. 


\section{EFFECT OF EMPLOYING DIFFERENT MAGNETIC MATERIALS IN THE NEW MR PISTON DESIGN}

This section is dedicated to discussing the effects of employing different magnetic materials in the new MR piston design. This shows the reasons for employing the new materials in the current study, namely, the Vacoflux-50 and the AMTSmartec $^{+}$MR fluid. The damper performance is evaluated based on the current FEA of the damper due to the employment of different materials and MR fluids. The available $B-H$ curves of the materials and MR fluids presented in Fig. 16, Fig. 19, and Fig. 21 were used to define the nonlinear magnetic properties in the materials and fluids investigated. The comparisons have been performed for two types of MR fluids, namely the MRF-140CG MR fluid and the MRHCCS4-B MR fluid, and different magnetic alloys that include magnetic stainless steel and iron-cobalt alloys. The study has been performed at different input currents in order to show the nonlinear effects of each design parameter.

The results of these investigations are presented by Table 4 to Table 6. The tables show the variations of different design parameters at input currents $I=0.5 \mathrm{~A}, I=1.0 \mathrm{~A}$, and $I=2.0 \mathrm{~A}$, respectively. The design parameters investigated are the magnetic field density at the farthermost locations of the piston, the corresponding variation in fluid yield stress, and the average magnetic field density in the MR fluid region. The fielddependent yield stress data of the MRHCCS4-B MR fluid was not available to the authors. However, it is thought that the yield stress is considerably lower than the MRF-140CG MR fluid.

The effects of employing the aforementioned two types of MR fluids in comparison with the AMT-Smartec ${ }^{+}$MR fluid are shown in Fig. 35. Fig. 35 (a) shows the distributions of magnetic field in the MR fluid region for the three MR fluids at input current $I=0.4 \mathrm{~A}$, whereas Fig. 35 (b) shows those distributions at $I=2.0$ A. It can be shown that the AMTSmartec $^{+}$MR fluid exhibits higher field densities compared to the other fluids. The nonlinear variation of the distribution of magnetic field with the increase of input current can be shown by the comparison of both figures. The AMT-Smartec ${ }^{+}$MR fluid is shown to be more affected by magnetic saturation compared to the other fluids as can be shown from the magnetic field distribution in the middle region in both figures. This shows the importance of defining the nonlinear magnetic properties of MR fluids via the $B-H$ curves available for MR fluids, as it is thought that the definition of a fixed value of the magnetic relative permeability of MR fluids in similar models may affect the distribution of magnetic field in the MR piston.

The effects of employing different magnetic materials in the piston head are shown in Fig. 36. Fig. 36(a) shows the distributions of magnetic field in the MR fluid region for three alloys of magnetic stainless steel in comparison with Vacoflux50, whereas Fig. 36(b) shows that comparison between Vacoflux-50 and four different iron-cobalt alloys. The $B-H$ curves available for the different magnetic materials presented in Fig. 16, Fig. 19 have been used to define the material properties in the current FE model. The comparisons are implemented at input current $I=2.0$ A. However, the investigations at different input currents are presented in Table 4 to Table 6.

Moreover, the effect of replacing the aluminium inner part in the piston with Vacoflux-50, which was not possible in the current study due to the limitation of machining capabilities, has been investigated and the results are also shown in Table 4 to Table 6. As expected, the employment of a Vacoflux-50 magnetic core increases the magnetic field in the MR fluid region considerably, compared to the original design. The magnetic field density at the locations of piston shoulders is predicted to increase by $2.5 \%$ at $I=0.5 \mathrm{~A}, 14.6 \%$ at $I=1.0 \mathrm{~A}$, and $13.7 \%$ at $I=2.0 \mathrm{~A}$. That increase leads to a corresponding increase of fluid yield stress at the same locations by $3.34 \%$, $15.1 \%$, and $15.8 \%$, respectively.

It can be seen from this analysis that the employment of all materials and MR fluids investigated in this section lead to reduce the magnetic field density, and consequently the fluid yield stress, compared to the original design that employs the Vacoflux-50 and the AMT-Smartec ${ }^{+}$MR fluid. The only increase in magnetic field has been achieved when the whole piston core has been made of Vacoflux-50, which was not possible in this study. Also, the variations of magnetic properties are also shown to be nonlinear due to the different $B$ $-H$ curves for the materials.

\section{CONCLUSIONS}

In the presented paper, the roles of different magnetic characteristics of materials and piston design in improving the performance of MR dampers are analysed based on theoretical predictions and experimental measurements. The importance of the nonlinear modelling and simulation of magnetic materials for MR dampers is highlighted in the current FE model. On the other hand, the presented analytical dynamic model shows that the behaviour of MR dampers under cyclic excitations is affected by the fluid compressibility and existence of air pocket and air bubbles. Moreover, and a novel design of an MR piston that incorporates some enhanced magnetic characteristics has been developed and tested.

The current FE model presented for the new MR piston accounts for the inclusion of the nonlinear magnetic properties of the different materials. The $B-H$ curves available for the magnetic material and the MR fluid were used to define the material properties. The fixed values of magnetic permeability of different magnetic materials defined in some studies such as $[17,43-45,50,51]$ are thought to affect the magnetic field distribution in MR devices even at low DC currents. Therefore, the inclusion of nonlinear magnetic characteristics in numerical modelling and analyses of magnetic circuits of MR devices is thought to be necessary.

The suggested modifications in the new design are: the usage of the high permeability Vacoflux-50 magnetic material, the usage of the AMT-Smartec ${ }^{+}$MR fluid, and the configuration of the MR fluid through the coil bobbin. The advantages of each of these design and material changes, in terms of the magnetic characteristics, have been shown. The employment of the Vacoflux-50 magnetic material and the AMT-Smartec ${ }^{+}$MR 
fluid is not frequently reported in the literature for MR applications.

It was found that the employment of the different design modifications affects the magnetic field distribution in the previously-tested MR damper in $[1,14,17]$ by different values, as presented in Table 3. The employment of all the suggested modifications is shown to increase the magnetic field density at the extreme locations of the MR fluid region of the previouslytested MR damper by $220 \%$, compared to the original design presented in $[1,14,17]$. Therefore, the maximum force of the damper has been predicted to increase by $550 \%$, under the same excitation frequency of $f=0.5 \mathrm{~Hz}$, and the applied current of $I$ $=1.0$ A reported in $[1,14,17]$. This massive increase is mainly due to the replacement of the MR fluid made in-house in $[1,14$, 17], with the AMT-Smartec ${ }^{+}$MR fluid, as the latter exhibits very high permeability and fluid yield stress at very low input currents. The percentage increase in fluid yield stress has been found to be further higher at lower input currents.

The flow of the MR fluid in the MR damper under cyclic load has been investigated by a one-dimensional parametric dynamic model. It is shown that the model predicts the damper behaviour to an acceptable degree of accuracy, in comparison with the available experimental data in $[17,18]$. It can be concluded that the compressibility effects due to gas existence in the form of an air pocket in the compression chamber and air bubbles in the rebound chamber mainly form the hysteretic behaviour of the MR damper. Most models presented in the available literature simplify the determination of $Q$ from the kinematics of the piston head assuming incompressible flow, $Q=A \dot{x}$. However, the current model predicts the actual volumetric flow rate based on the pressure difference between the chambers and the effect of fluid compressibility.

It has been shown that the proposed design of the new MR piston exhibits high magnetic field at low input currents. That is due to the high permeability of the magnetic material and the fluid employed, as can be seen from the comparisons with other materials presented in Table 4 to 6 . Therefore, the current design is thought to be more suitable for relatively higher loads.

Finally, it is believed that the presented FE/analytical approach extends some understanding to the nonlinear behaviour of MR dampers under cyclic loads. This nonlinear behaviour is due to the nonlinear magnetic properties of MR piston which has been predicted by the current FE model, and also due to the effects of fluid compressibility and existence of air in some designs of MR dampers that have been predicted by the current analytical model of fluid flow in the damper. Moreover, the analyses of the suggested design and material changes highlight the role of the magnetic characteristics of different materials used in MR dampers. Future work may investigate a fully-coupled numerical analysis of MR dampers to account for the effect of the variable magnetic field density in the MR fluid region. Also, an optimisation study, whose objective is to analyse the optimum dimensions of the piston which lead to the maximum output force is planned as a future work of the current study. Several design parameters may affect the output force, namely the width of magnetic poles, thickness and length of the throttling area, number of active coils, and coil wire diameter, whose minimum value is one of the design constraints in order to achieve the required number of coil turns within the dimensions of the piston. Moreover, experimental analysis of the behaviour of the novel damper under different load and motion conditions is required and also planned as a future work of the current study.

\section{ACKNOWLEDGEMENT}

The authors would like to acknowledge the valuable support from Vacuumschmelze GmbH in Germany, for supporting this research with the necessary materials, technical data, and heat treatments. The first author acknowledges the great support obtained from the Egyptian government to this project.

\section{REFERENCES}

[1] W.W. Chooi and S.O. Oyadiji. "Design, modelling and testing of magnetorheological (MR) dampers using analytical flow solutions", in Computers and Structures, vol. 86, 2008, pp. 473482.

[2] G. Xinchun, H. Yonghu, R. Yi, L. Hui, and O. Jinping. "A novel self-powered MR damper: theoretical and experimental analysis", in Smart Materials and Structures, vol. 24, 2015, p. 105033.

[3] Y. Zhang and S.O. Oyadiji. "Comparisons of the dynamic characteristics of magnetorheological and hydraulic dampers". In Proceedings of SPIE 9431, Smart Structures and Materials + Nondestructive Evaluation and Health Monitoring. 2015. California, United States: SPIE.

[4] J. Gołdasz and B. Sapiński. "Magnetostatic Analysis of a Pinch Mode Magnetorheological Valve", in Acta Mechanica et Automatica, vol. 11, 2017, pp. 229-232.

[5] A. Bompos and G. Nikolakopoulos. "CFD simulation of magnetorheological fluid journal bearings", in Simulation Modelling Practice and Theory, vol. 19, 2011, pp. 1035-1060.

[6] J. Gołdasz and B. Sapiński, Insight into Magnetorheological Shock Absorbers. Switzerland: Springer. 2015.

[7] M. Ashtiani, S.H. Hashemabadi, and A. Ghaffari. "A review on the magnetorheological fluid preparation and stabilization", in Journal of Magnetism and Magnetic Materials, vol. 374, 2015, pp. 716730 .

[8] S.G. Sherman, D.A. Paley, and N.M. Wereley. "Parallel Simulation of Transient Magnetorheological Direct Shear Flows Using Millions of Particles", in IEEE Transactions on Magnetics, vol. 48, 2012, pp. 3517-3520.

[9] Y.B. Kazakov, N.A. Morozov, and S.A. Nesterov. "Development of models of the magnetorheological fluid damper", in Journal of Magnetism and Magnetic Materials, vol. 431, 2017, pp. 269-272.

[10] J. Li, C. Qin, S. Guo, and J. Wang, Magnetic circuit design and performance analysis of a rotary magnetorheological damper with new structure, in IEEE International Conference on Cybernetics and Intelligent Systems (CIS) and IEEE Conference on Robotics, Automation and Mechatronics (RAM), G. Yang, Editor. 2017, IEEE Ningbo, China. p. 524-529.

[11] A. Dorfmann, R.W. Ogden, and A.S. Wineman. "A threedimensional non-linear constitutive law for magnetorheological fluids, with applications", in International Journal of Non-Linear Mechanics, vol. 42, 2007, pp. 381-390.

[12] Ş. Çeşmeci and T. Engin. "Modeling and testing of a fieldcontrollable magnetorheological fluid damper", in International Journal of Mechanical Sciences, vol. 52, 2010, pp. 1036-1046.

[13] P. Guo, X. Guan, and J. Ou. "Physical modeling and design method of the hysteretic behavior of magnetorheological dampers", in Journal of Intelligent Material Systems and Structures, vol. 25, 2013, pp. 680-696.

[14] W.W. Chooi and S.O. Oyadiji. "Mathematical Modeling, Analysis, and Design of Magnetorheological (MR) Dampers", in Journal of Vibration and Acoustics, vol. 131, 2009, p. 061002. 
[15] W. Ata, Intelligent Control of Tracked Vehicle Suspension. 2014, The University of Manchester: UK.

[16] X.-X. Bai, W. Hu, and N.M. Wereley. "Magnetorheological Damper Utilizing an Inner Bypass for Ground Vehicle

Suspensions", in IEEE Transactions on Magnetics, vol. 49, 2013, pp. 3422-3425.

[17] W.W. Chooi, Experimental characterisation of the properties of magnetorheological (MR) fluids and MR damper. 2005, The University of Manchester: UK.

[18] W.W. Chooi and S.O. Oyadiji. "Experimental Testing and Validation of a Magnetorheological (MR) Damper Model", in Journal of Vibration and Acoustics, vol. 131, 2009, p. 061003.

[19] D. Case, B. Taheri, and E. Richer. "Multiphysics modeling of magnetorheological dampers", in International Journal of Multiphysics, vol. 7, 2013, pp. 61-76.

[20] P. Czop and J. Gniłka. "Reducing aeration and cavitation effect in shock absorbers using fluid-structure interaction simulation", in Computer Assisted Methods in Engineering and Science, vol. 23, 2017, pp. 171-189.

[21] Dow Corning, Compressibility data. Data supplied by the company in 22 November 2018.

[22] H. Sahin, F. Gordaninejad, X. Wang, and Y. Liu. "Response time of magnetorheological fluids and magnetorheological valves under various flow conditions", in Journal of Intelligent Material Systems and Structures, vol. 23, 2012, pp. 949-957.

[23] H. Singh, W. Hu, N. Wereley, and W. Glass. "Experimental validation of a magnetorheological energy absorber design optimized for shock and impact loads", in Smart Materials and Structures, vol. 23, 2014, p. 125033.

[24] M.H. Idris, F. Imaduddin, S.A. Mazlan, and S.-B. Choi. "A Concentric Design of a Bypass Magnetorheological Fluid Damper with a Serpentine Flux Valve", in Actuators, vol. 9, 2020, p. 16.

[25] W.H. Liao and C.Y. Lai. "Harmonic analysis of a magnetorheological damper for vibration control", in Smart Materials and Structures, vol. 11, 2002, pp. 288-296.

[26] K. Kim, Z. Chen, D. Yu, and C. Rim. "Design and experiments of a novel magneto-rheological damper featuring bifold flow mode", in Smart Materials and Structures, vol. 25, 2016, p. 075004.

[27] Wikipedia, the free encyclopedia, Permeability (electromagnetism). Available at:

https://en.wikipedia.org/wiki/Permeability_(electromagnetism).

[28] O. Macháček, Magnetorheological Strut for Vibration Isolation System of Space Launcher, in Faculty of Mechanical Engineering/ Institute of Machine and Industrial Design. 2019, Brno University of Technology: Czech Republic.

[29] Wikipedia, the free encyclopedia, Permendur. Available at: https://en.wikipedia.org/wiki/Permendur.

[30] Vacuumschmelze GmbH, Vacoflux - magnetic properties datasheet. Available at:

https://vacuumschmelze.de/Produkte/WeichmagnetischeWerkstoffe-und-Stanzteile/49-Kobalt-Eisen---VACOFLUX-undVACODUR.

[31] C.P. Steinmetz, Theory and calculation of alternating current phenomena. Alternating current pheonomena., United States: McGraw-Hill Book Company. 1916.

[32] P. Oxley, J. Goodell, and R. Molt. "Magnetic properties of stainless steels at room and cryogenic temperatures", in Journal of Magnetism and Magnetic Materials, vol. 321, 2009, pp. 21072114.

[33] COMSOL, COMSOL Multiphysics Reference Manual. Sweden: COMSOL Inc. 2018.

[34] Vacuumschmelze $\mathrm{GmbH}$, Soft magnetic cobalt-iron alloys, Vacoflux and Vacodur datasheet. Available at: https://vacuumschmelze.com/Assets/Cobalt-Iron\%20Alloys.pdf.

[35] Vacuumschmelze $\mathrm{GmbH}$, Vacoflux 27 preliminary datasheet datasheet. Available at: https://indico.cern.ch/event/682107/attachments/1560598/2465487 /VACOFLUX_27_preliminary_datasheet.pdf.

[36] J.P. Goldasz, Z.W. Szklarz, A.A. Alexandridis, T.W. Nehl, F. Deng, and O. Valee, High-performance piston core for a magnetorheological damper, U.S. Patent, Editor. 2005, Google Patents: USA.
[37] M. Kubík, Magnetorheological Suspension Damper for Space Application, in Faculty of Mechanical Engineering/Institute of Machine and Industrial Design. 2018, Brno University of Technology: Czech Republic.

[38] J. Goldasz, Study of a modular magnetorheological valve, in 18th International Carpathian Control Conference (ICCC), D. Popescu, Editor. 2017, IEEE: Sinaia, Romania. p. pp. 306-309.

[39] Lord Corporation, MRF-132DG Magneto-Rheological Fluid datasheet. Available at:

https://www.lord.com/sites/default/files/Documents/TechnicalData Sheet/DS7015_MRF-132DGMRFluid.pdf.

[40] Arus MR Tech, AMT-Smartec ${ }^{+}$datasheet. Available at: https://secureservercdn.net/160.153.137.16/1jc.c8f.myftpupload.co $\mathrm{m} /$ wp-content/uploads/2018/09/smartec_tds_pdf.pdf.

[41] C.R. Liao, D.X. Zhao, L. Xie, and Q. Liu. "A design methodology for a magnetorheological fluid damper based on a multi-stage radial flow mode", in Smart Materials and Structures, vol. 21, 2012, p. 085005.

[42] Liquids research Ltd, Magnetorheological Fluids datasheet. Available at: https://liquidsresearch.com/enGB/document_download-58.aspx.

[43] H. Park, H. Kim, S. Shin, and S.-B. Choi. "A comparative work on vibration control of a quarter car suspension system with two different magneto-rheological dampers", in Smart Materials and Structures, vol. 26, 2017, p. 015009.

[44] T.-H. Lee, C. Han, and S.-B. Choi. "Design and damping force characterization of a new magnetorheological damper activated by permanent magnet flux dispersion", in Smart Materials and Structures, vol. 27, 2018, p. 015013.

[45] A. Syrakos, Y. Dimakopoulos, and J. Tsamopoulos. "Theoretical study of the flow in a fluid damper containing high viscosity silicone oil: Effects of shear-thinning and viscoelasticity", in Physics of Fluids, vol. 30, 2018, p. 030708.

[46] J.S. Kumar, P.S. Paul, G. Raghunathan, D.G.J.I.J.o.M. Alex, and M. Engineering. "A review of challenges and solutions in the preparation and use of magnetorheological fluids", in International Journal of Mechanical and Materials Engineering, vol. 14, 2019, p. 13.

[47] T. Aravind, N. Arunachalam, and A.X. Kennedy. "Physical insights about magnetic flux distribution and its effect on surface roughness in MR fluid based finishing process", in Materials Research Express, vol. 6, 2018, p. 016104.

[48] Vacuumschmelze GmbH, Laboratory measurements of the magnetisation curves of Vacoflux 50 at different temperatures. Data supplied by the company in 15 March 2019.

[49] M. Kubík, M. Ondřej, S. Zbyněk, R. Jakub, N. Petr, and M. Ivan, Transient Magnetic Model of Magnetorheological Damper and Its Experimental Verification, in 4th International Conference on Mechatronics and Mechanical Engineering (ICMME 2017), P. Tandon, W. Wisnoe, and M.Z. Bin Abdullah, Editors. 2018, EDP Sciences: Kuala Lumpur, Malaysia. p. pp. 06002.

[50] R.M. Desai, M.E.H. Jamadar, H. Kumar, S. Joladarashi, and R. Sekaran. "Design and experimental characterization of a twin-tube MR damper for a passenger van", in Journal of the Brazilian Society of Mechanical Sciences and Engineering, vol. 41, 2019, p. 332.

[51] F. Gao, Y.-N. Liu, and W.-H. Liao. "Optimal design of a magnetorheological damper used in smart prosthetic knees", in Smart Materials and Structures, vol. 26, 2017, p. 035034. 
TABLE 1

MAIN DIMENSIONS (IN MM) OF THE DEVELOPED MR DAMPER IN [1, 14, 17]

\begin{tabular}{ll|ll}
\hline \hline $\begin{array}{l}\text { Radius of the piston rod, } \\
R_{o}\end{array}$ & $=4.5$ & $\begin{array}{l}\text { Inner radius of piston } \\
\text { gap, } R_{1}\end{array}$ & $=24$ \\
$\begin{array}{l}\text { Outer radius of piston gap, } \\
R_{2}\end{array}$ & $\begin{array}{l}\text { Outer radius of piston, } \\
R_{4}\end{array}$ & $=40$ \\
$\begin{array}{l}\text { Inner radius of the annular } \\
\text { cylinder, } R_{5}\end{array}$ & $=50$ & Piston height, $L_{\text {pis }}$ & $=82$ \\
$\begin{array}{l}\text { Active length of the coil, } \\
L_{\text {active }}\end{array}$ & $=10$ & $\begin{array}{l}\text { Distance between the } \\
\text { coils, } L_{c}\end{array}$ & $=20$ \\
\hline
\end{tabular}

TABLE 2

PARAMETERS OF THE FE MODEL OF THE NOVEL MR PISTON

\begin{tabular}{ll}
\hline \hline Radius of the inner aluminium core, $R_{O}$ & $=7.5 \mathrm{~mm}$ \\
Radius of the inner Vacoflux-50 core, $R_{1}$ & $=15 \mathrm{~mm}$ \\
Outer radius of the MR fluid region, $R_{2}$ & $=18 \mathrm{~mm}$ \\
Input current, $I$ & $=2 \mathrm{~A}$ \\
Electric conductivity of the MR fluid, $\sigma_{M R}$ & $=10-11 \mathrm{~S} / \mathrm{m}$ \\
Electric conductivity of Vacoflux-50, $\sigma_{V X}$ & $=2.4 \times 106 \mathrm{~S} / \mathrm{m}$ \\
Number of turns of each coil, $n_{T}$ & $=350$ \\
Thickness of the extreme Vacoflux-50 spacers, $L_{p o l e}$ & $=10 \mathrm{~mm}$ \\
Thickness of the intermediate Vacoflux-50 spacers, & $=6 \mathrm{~mm}$ \\
$L_{\text {mid }}$ & $=21 \mathrm{~mm}$ \\
Outer radius of the nylon-66 insulator, $R_{3}$ & $=32 \mathrm{~mm}$ \\
Outer radius of the Vacoflu-50 spacers, $R_{4}$ & $=37.5 \mathrm{~mm}$ \\
Outer radius of the Vacoflux-50 casing, $R_{5}$ & $=40 \mathrm{~mm}$ \\
Outer radius of the aluminium covers, $R_{6}$ &
\end{tabular}

\begin{tabular}{|c|c|c|c|c|c|c|}
\hline \multirow{5}{*}{$\begin{array}{l}\text { ङ } \\
0 \\
i \\
\text { II } \\
-1\end{array}$} & \multicolumn{2}{|c|}{ Increase of $\tau_{y}(\%)$} & $\stackrel{\check{I}}{\dot{I}}$ & 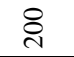 & $\ddot{n}$ & $\stackrel{\vartheta}{=}$ \\
\hline & 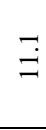 & $\begin{array}{c}\text { Corresponding yield } \\
\text { stress of MR fluid at } \\
\text { shoulders, } \tau_{y}(\mathrm{kPa})\end{array}$ & $\stackrel{\hat{i}}{i}$ & $\dot{m}$ & $\stackrel{\infty}{\stackrel{\infty}{=}}$ & $\stackrel{\substack{m \\
⿱ 亠 凶 禸}}{+}$ \\
\hline & $\begin{array}{l}0 \\
\text { క. } \\
0\end{array}$ & $\begin{array}{l}\text { Average field in MR } \\
\text { fluid region, } B_{a v}(\mathrm{~T})\end{array}$ & $\underset{\infty}{=}$ & $\frac{\mathfrak{n}}{\infty}$ & $\begin{array}{l}\vec{n} \\
\infty \\
0 \\
0\end{array}$ & $\underset{\infty}{\frac{ \pm}{0}}$ \\
\hline & \multicolumn{2}{|c|}{ Increase of $B_{s h}(\%)$} & $\stackrel{0}{r}$ & $\underline{n}$ & $\vec{m}$ & $\underset{\infty}{\tilde{i}}$ \\
\hline & $\stackrel{n}{\tilde{n}}$ & $\begin{array}{c}\text { Magnetic field density } \\
\text { (strength) at } \\
\text { shoulders, } B_{s h}(\mathrm{~T}), \\
\left(H_{s h}\right)(\mathrm{A} / \mathrm{m}) \\
\end{array}$ & ָָ & 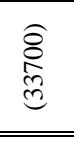 & $\stackrel{\sqrt[n]{n}}{0}$ & 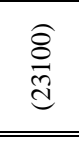 \\
\hline \multirow{5}{*}{$\begin{array}{l}\frac{3}{n} \\
\frac{n}{11}\end{array}$} & \multicolumn{2}{|c|}{ Increase of $\tau_{y},(\%)$} & 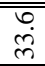 & 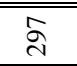 & $\begin{array}{l}\dot{0} \\
i\end{array}$ & $\stackrel{\text { d }}{t}$ \\
\hline & 京 & $\begin{array}{l}\text { Corresponding yield } \\
\text { stress of MR fluid at } \\
\text { shoulders, } \tau_{y}(\mathrm{kPa})\end{array}$ & $\underset{\infty}{\bullet}$ & ì & $\stackrel{n}{\infty}$ & $\stackrel{\vec{v}}{\ddot{\lambda}}$ \\
\hline & in & $\begin{array}{l}\text { Average field in MR } \\
\text { fluid region, } B_{a v},(\mathrm{~T})\end{array}$ & 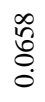 & $\begin{array}{l}\stackrel{2}{ \pm} \\
\stackrel{+}{0}\end{array}$ & 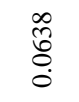 & $\begin{array}{l}\hat{0} \\
\stackrel{1}{0}\end{array}$ \\
\hline & \multicolumn{2}{|c|}{ Increase of $B_{s h}(\%)$} & $\stackrel{\bullet}{\bullet}$ & ஜิ & ๙ุ & $\stackrel{t}{m}$ \\
\hline & $\begin{array}{l}0 \\
\infty \\
0 \\
0 \\
0\end{array}$ & $\begin{array}{c}\text { Magnetic field density } \\
\text { (strength) at } \\
\text { shoulders, } B_{s h}(\mathrm{~T}), \\
\left(H_{s h}\right)(\mathrm{A} / \mathrm{m}) \\
\end{array}$ & $\stackrel{m}{n}$ & $\begin{array}{l}\text { } \\
\text { o } \\
\text { d }\end{array}$ & $\stackrel{\infty}{\infty}$ & $\begin{array}{l}\text { ̊े } \\
\text { तิ } \\
\text { ป̂d }\end{array}$ \\
\hline \multirow{5}{*}{$\begin{array}{l}\underset{3}{ङ} \\
0 \\
\stackrel{0}{11} \\
-1\end{array}$} & \multicolumn{2}{|c|}{ Increase of $\tau_{y},(\%)$} & $\vec{b}$ & \& & 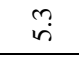 & हु \\
\hline & $\stackrel{n}{n}$ & $\begin{array}{c}\text { Corresponding yield } \\
\text { stress of MR fluid at } \\
\text { shoulders, } \tau_{y}(\mathrm{kPa})\end{array}$ & 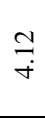 & $\stackrel{\infty}{=}$ & $\stackrel{े}{m}$ & $\stackrel{\text { กิ }}{\mathrm{N}}$ \\
\hline & $\stackrel{\infty}{\infty}$ & $\begin{array}{l}\text { Average field in MR } \\
\text { fluid region, } B_{a v},(\mathrm{~T})\end{array}$ & 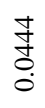 & $\begin{array}{l}\hat{\circ} \\
\stackrel{0}{0} \\
0\end{array}$ & $\begin{array}{l}0 \\
\stackrel{1}{0} \\
\text { Oे }\end{array}$ & 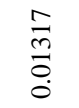 \\
\hline & \multicolumn{2}{|c|}{ Increase of $B_{s h}(\%)$} & $\stackrel{\infty}{\stackrel{\infty}{\sim}}$ & $\underset{8}{0}$ & $\stackrel{\infty}{i}$ & ปั \\
\hline & $\stackrel{\infty}{\stackrel{\infty}{c}}$ & $\begin{array}{c}\text { Magnetic field density } \\
\text { (strength) at } \\
\text { shoulders, } B_{s h}(\mathrm{~T}), \\
\left(H_{s h}\right)(\mathrm{A} / \mathrm{m}) \\
\end{array}$ & $\stackrel{n}{\stackrel{n}{+}}$ & ڤ్రి & $\frac{\sqrt{2}}{\stackrel{1}{0}}$ & $\begin{array}{l}\text { } \\
\stackrel{\infty}{0} \\
\stackrel{d}{d}\end{array}$ \\
\hline \multirow{5}{*}{$\begin{array}{l}3 \\
\vdots \\
0 \\
11 \\
-1\end{array}$} & \multicolumn{2}{|c|}{ Increase of $\tau_{y},(\%)$} & $\stackrel{r}{\dot{m}}$ & 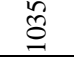 & $\stackrel{r}{\dot{r}}$ & $\stackrel{n}{I}$ \\
\hline & $\stackrel{1}{\infty}$ & $\begin{array}{l}\text { Corresponding yield } \\
\text { stress of MR fluid at } \\
\text { shoulders, } \tau_{y}(\mathrm{kPa})\end{array}$ & $\exists$ & $\ddot{\sigma}$ & $\begin{array}{l}\substack{0 \\
\infty \\
0} \\
0\end{array}$ & $\stackrel{\vartheta}{\dot{J}}$ \\
\hline & $\stackrel{9}{0}$ & $\begin{array}{l}\text { Average field in MR } \\
\text { fluid region, } B_{a v}(\mathrm{~T})\end{array}$ & 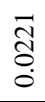 & 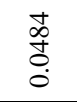 & $\stackrel{m}{\stackrel{m}{0}}$ & $\stackrel{\infty}{\circ}$ \\
\hline & \multicolumn{2}{|c|}{ Increase of $B_{s h}(\%)$} & $\stackrel{n}{n}$ & $\underline{n}$ & $n$ & ๓ి \\
\hline & $\ddot{8}$ & $\begin{array}{c}\text { Magnetic field density } \\
\text { (strength) at } \\
\text { shoulders, } B_{S h}(\mathrm{~T}) \\
\left(H_{s h}\right)(\mathrm{A} / \mathrm{m})\end{array}$ & $\stackrel{n}{\frac{n}{0}}$ & 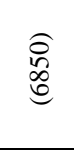 & 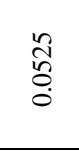 & 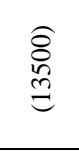 \\
\hline \multicolumn{2}{|c|}{ 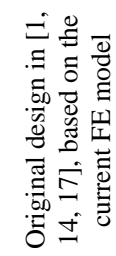 } & & 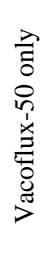 & 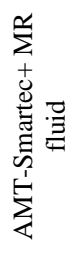 & 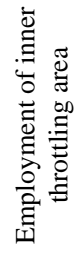 & 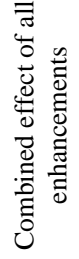 \\
\hline
\end{tabular}


TABLE 4

INVESTIGATION OF DIFFERENT MAGNETIC MATERIALS IN THE NEW DESIGN

\begin{tabular}{|c|c|c|c|c|c|}
\hline \multicolumn{6}{|c|}{$I=0.5(\mathrm{~A})$} \\
\hline $\begin{array}{c}\text { Proposed design } \\
\text { using Vacoflux- } \\
50 \text { and AMT- } \\
\text { Smartec+ MRF }\end{array}$ & 0.473 & \multirow{2}{*}{ 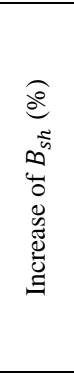 } & 0.086 & 25.9 & \multirow{2}{*}{ 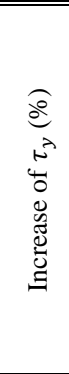 } \\
\hline $\begin{array}{l}\text { Modifications of } \\
\text { magnetic materials }\end{array}$ & 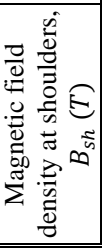 & & 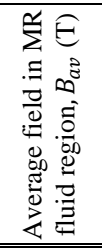 & 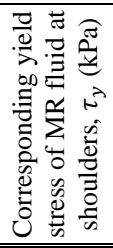 & \\
\hline \multicolumn{6}{|l|}{ Different MR fluids } \\
\hline MRF -140CG & 0.286 & -39.5 & 0.0602 & 14.2 & -45.2 \\
\hline MRHCCS4-B & 0.16 & -66.2 & 0.0328 & N/A & N/A \\
\hline $\begin{array}{l}\text { Piston rod in } \\
\text { Vacoflux-50 }\end{array}$ & 0.485 & 2.54 & 0.0887 & 26.8 & 3.34 \\
\hline \multicolumn{6}{|l|}{ Different MSS alloys } \\
\hline MSS 405 & 0.278 & -41.2 & 0.0517 & 15.9 & -38.6 \\
\hline MSS 416 & 0.146 & -69.1 & 0.0293 & 8.65 & -66.6 \\
\hline MSS 430 & 0.146 & -69.1 & 0.0294 & 8.7 & -66.4 \\
\hline \multicolumn{6}{|c|}{ Different iron-cobalt-vanadium alloys } \\
\hline Vacoflux-17 & 0.343 & -27.5 & 0.0628 & 19.1 & -26.1 \\
\hline Vacoflux-27 & 0.32 & -32.3 & 0.0587 & 17.9 & -30.7 \\
\hline Vacoflux-18HR & 0.308 & -34.8 & 0.0565 & 17.3 & -33.3 \\
\hline 2V Permendur & 0.425 & -10.1 & 0.0774 & 23.4 & -9.4 \\
\hline
\end{tabular}

TABLE 5

INVESTIGATION OF DIFFERENT MAGNETIC MATERIALS IN THE NEW DESIGN

\begin{tabular}{|c|c|c|c|c|c|}
\hline $\begin{array}{l}\text { Proposed design } \\
\text { using Vacoflux- } \\
50 \text { and AMT- } \\
\text { Smartec+ MRF } \\
\end{array}$ & 0.685 & $\widehat{e}$ & 0.1215 & 37.4 & $\widehat{e}$ \\
\hline $\begin{array}{c}\text { Modifications of } \\
\text { magnetic materials }\end{array}$ & 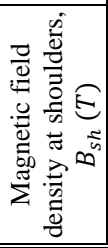 & $\begin{array}{l}\infty^{\tilde{n}} \\
\infty^{0} \\
0 \\
0 \\
\tilde{\Xi} \\
\tilde{0} \\
\Xi\end{array}$ & 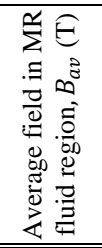 & 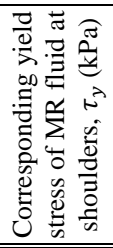 & 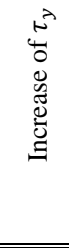 \\
\hline \multicolumn{6}{|l|}{ Different MR fluids } \\
\hline MRF -140CG & 0.455 & -33.6 & 0.0991 & 27 & -27.8 \\
\hline MRHCCS4-B & 0.3 & -56.2 & 0.0629 & N/A & N/A \\
\hline $\begin{array}{l}\text { Piston rod in } \\
\text { Vacoflux-50 } \\
\end{array}$ & 0.785 & 14.6 & 0.147 & 43.1 & 15.1 \\
\hline \multicolumn{6}{|l|}{ Different MSS alloys } \\
\hline MSS 405 & 0.458 & -33.1 & 0.0806 & 25.1 & -32.8 \\
\hline MSS 416 & 0.316 & -53.9 & 0.0612 & 17.7 & -52.6 \\
\hline MSS 430 & 0.292 & -57.4 & 0.0576 & 16.5 & -55.8 \\
\hline \multicolumn{6}{|c|}{ Different iron-cobalt-vanadium alloys } \\
\hline Vacoflux-17 & 0.532 & -22.3 & 0.093 & 29 & -22.2 \\
\hline Vacoflux-27 & 0.553 & -19.3 & 0.099 & 30.1 & -19.5 \\
\hline Vacoflux-18HR & 0.523 & -23.6 & 0.0933 & 28.7 & -23.4 \\
\hline 2V Permendur & 0.673 & -1.8 & 0.12 & 36.8 & -1.6 \\
\hline
\end{tabular}

TABLE 6

INVESTIGATION OF DIFFERENT MAGNETIC MATERIALS IN THE NEW DESIGN $I=2.0(\mathrm{~A})$

\begin{tabular}{|c|c|c|c|c|c|}
\hline $\begin{array}{l}\text { Proposed design } \\
\text { using Vacoflux- } \\
50 \text { and AMT- } \\
\text { Smartec+ MRF }\end{array}$ & 0.838 & e & 0.148 & 46.7 & e \\
\hline $\begin{array}{c}\text { Modifications of } \\
\text { magnetic materials }\end{array}$ & 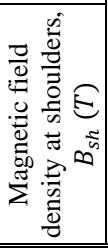 & 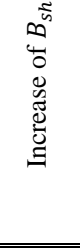 & 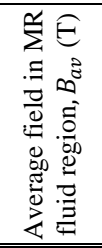 & 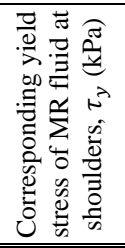 & 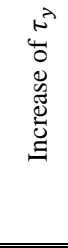 \\
\hline \multicolumn{6}{|l|}{ Different MR fluids } \\
\hline MRF -140CG & 0.62 & -26 & 0.1423 & 38.4 & -17.8 \\
\hline MRHCCS4-B & 0.485 & -42.1 & 0.1076 & N/A & N/A \\
\hline $\begin{array}{l}\text { Piston rod in } \\
\text { Vacoflux-50 }\end{array}$ & 0.953 & 13.7 & 0.1799 & 54 & 15.8 \\
\hline \multicolumn{6}{|l|}{ Different MSS alloys } \\
\hline MSS 405 & 0.57 & -32 & 0.1133 & 31.1 & -33.4 \\
\hline MSS 416 & 0.48 & -42.7 & 0.0997 & 26.3 & -43.7 \\
\hline MSS 430 & 0.455 & -45.7 & 0.0972 & 24.7 & -47 \\
\hline \multicolumn{6}{|c|}{ Different iron-cobalt-vanadium alloys } \\
\hline Vacoflux-17 & 0.665 & -20.6 & 0.1251 & 36.4 & -22.1 \\
\hline Vacoflux-27 & 0.72 & -14.1 & 0.1315 & 39.3 & -15.8 \\
\hline Vacoflux-18HR & 0.675 & -19.5 & 0.1256 & 37 & -20.7 \\
\hline 2V Permendur & 0.847 & 1.1 & 0.1535 & 47.3 & 1.2 \\
\hline
\end{tabular}

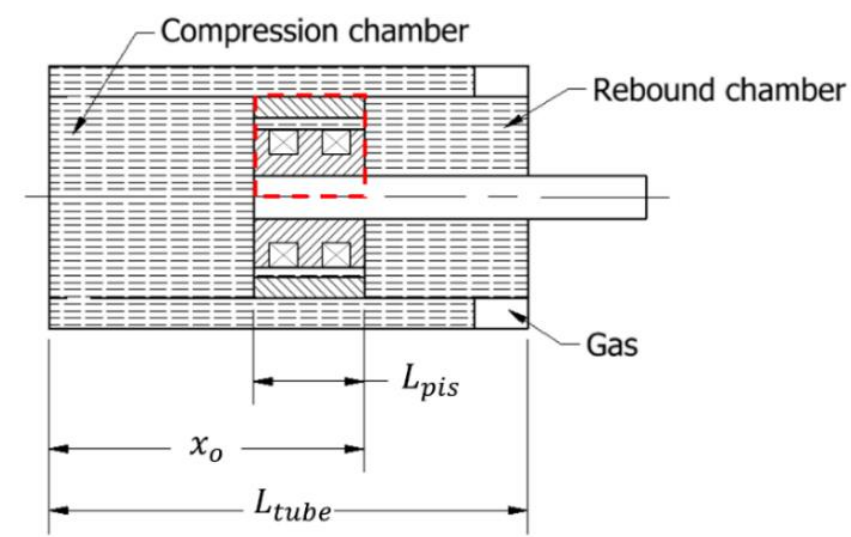

Fig. 1. A schematic drawing of the fluid domain of the MR damper (adapted from $[14,17])$.

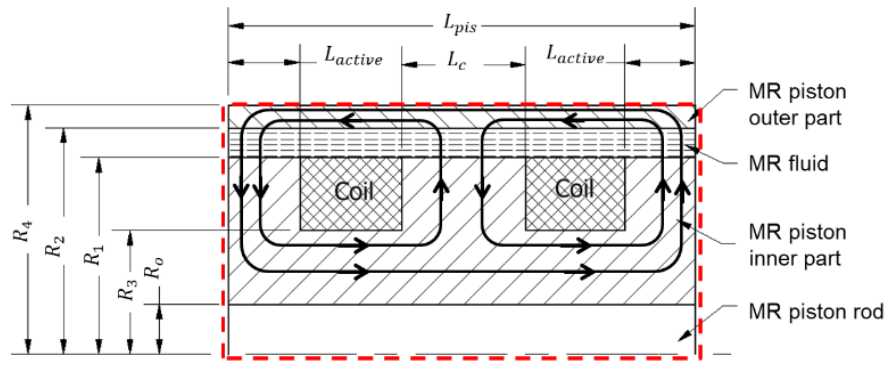

Fig. 2. A schematic drawing of the magnetic circuit (piston head) of the current MR damper (adapted from [14, 17]). 


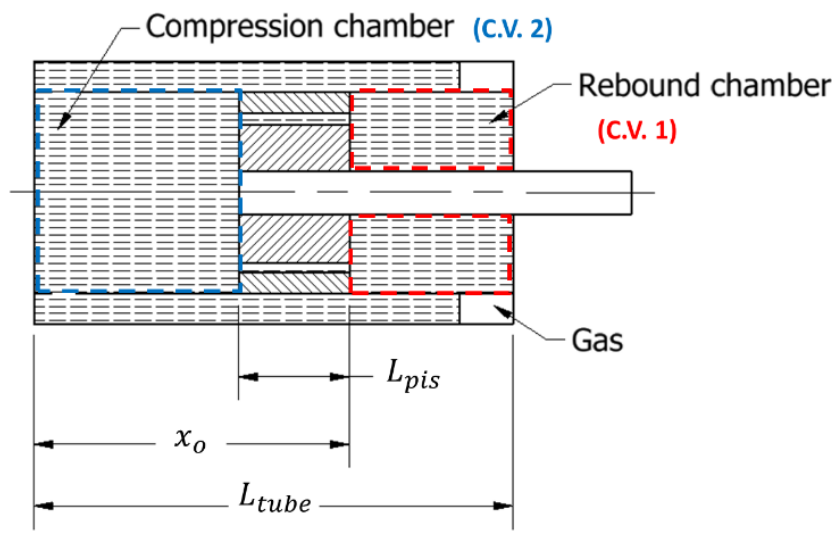

Fig. 3. Two control volumes assigned on the compression and the rebound chamber.

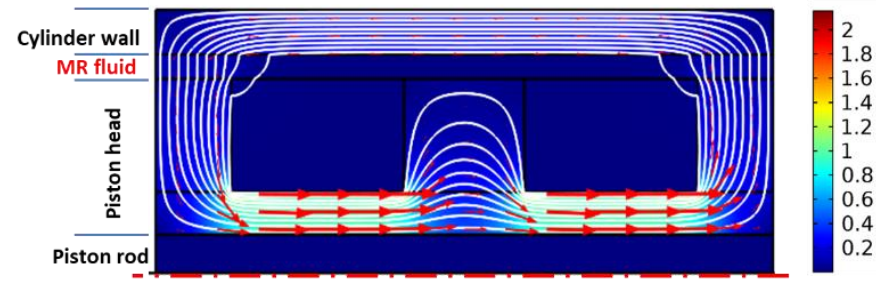

Fig. 4. Magnetic flux density in the piston; the magnetic flux is denser inside the coil bobbins and mainly flows across the MR fluid region at the extreme ends of the piston (magnetic poles). Units are in Tesla.

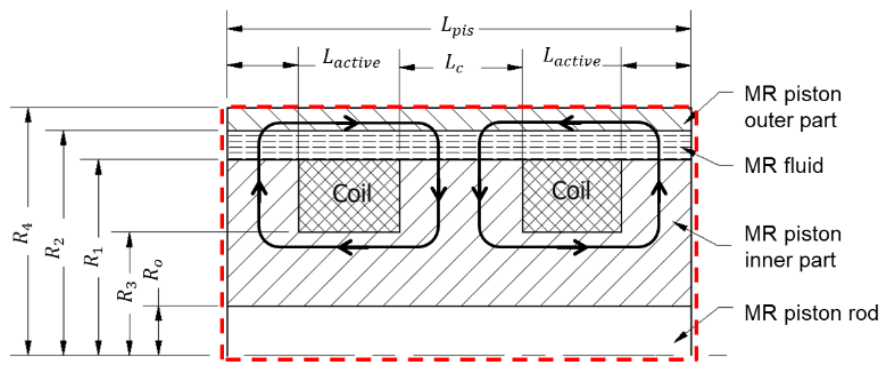

Fig. 5. A schematic drawing of magnetic flux contours in the current MR damper due to the coil configuration adopted in $[16,23]$.

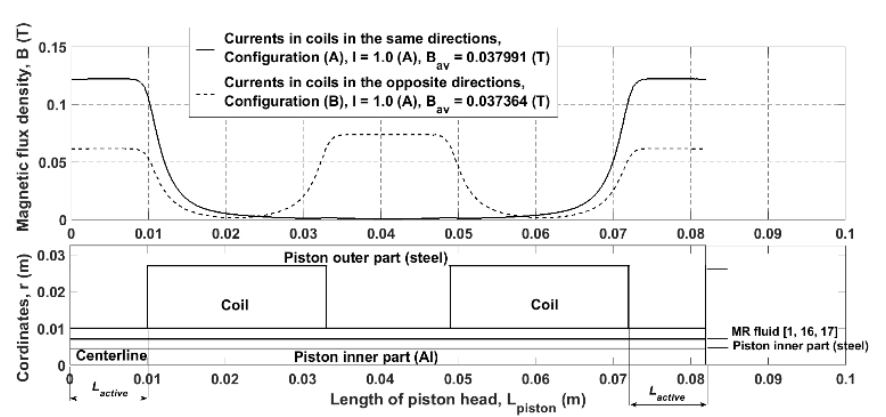

(a)

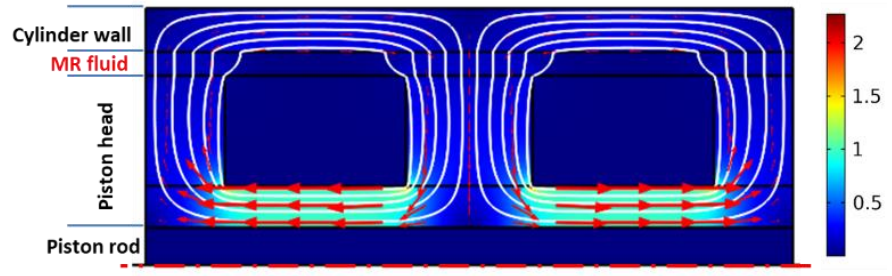

(b)

Fig. 6. Effect of current direction in the coils at $I=1.0 \mathrm{~A}$ : (a) magnetic field density in the MR fluid region due to same and opposite current directions, and (b) contours of magnetic flux density in the piston when the coils are operated with currents with opposite directions.

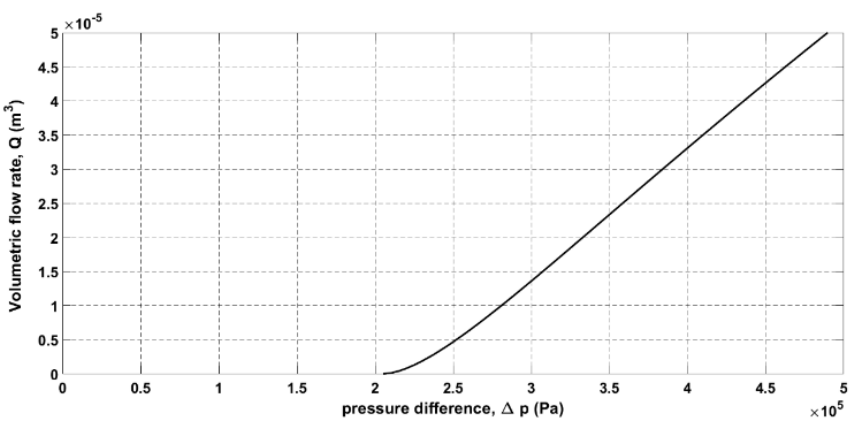

Fig. 7. The variation of the volumetric flow rate at different pressure differences between the chambers of the MR damper according to the quasi-static model.

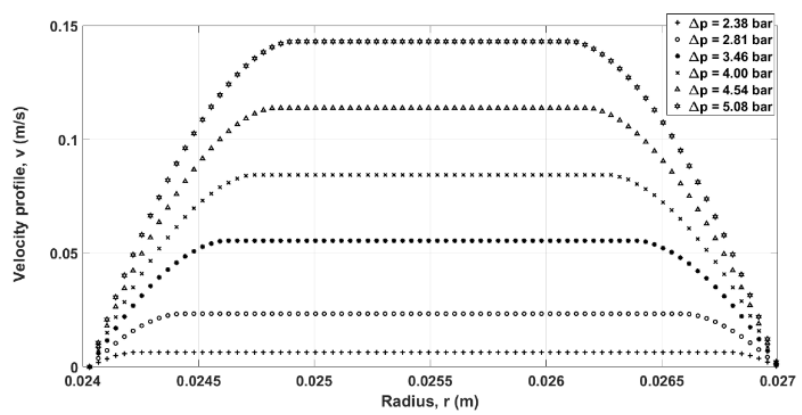

Fig. 8. Velocity profiles of the MR fluid in the damper throttling area at different pressure differences according to the quasi-static model. 


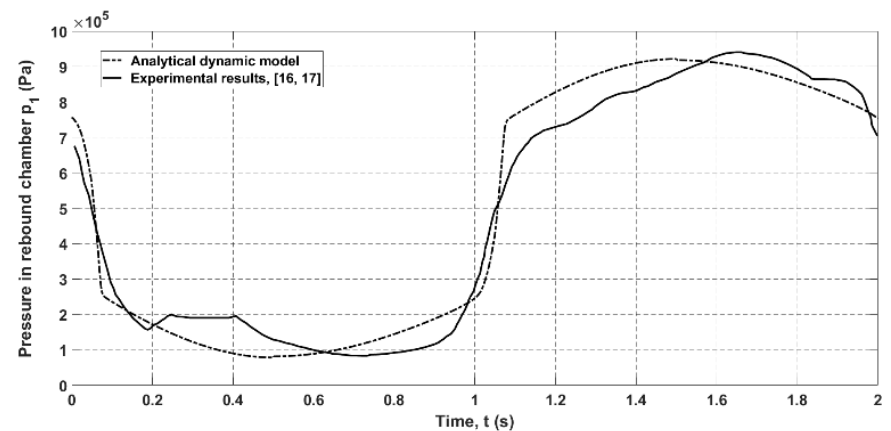

Fig. 9. Analytical pressure in the rebound chamber compared to the available experimental data in $[17,18]$. The time history shows a complete cycle of the piston sinusoidal motion.

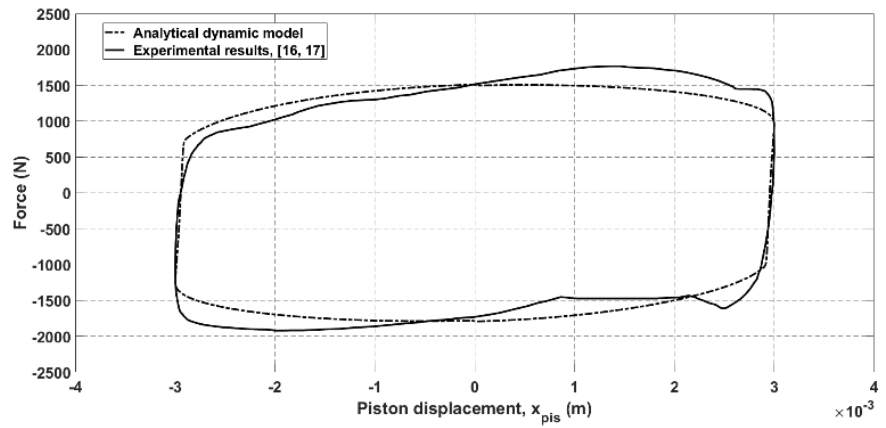

Fig. 10. Theoretical work diagram, $F-x$, according to the analytical dynamic model in comparison with the work diagram deduced from the experimental measurements of the pressures in the chambers of the previously-tested damper in $[17,18]$.

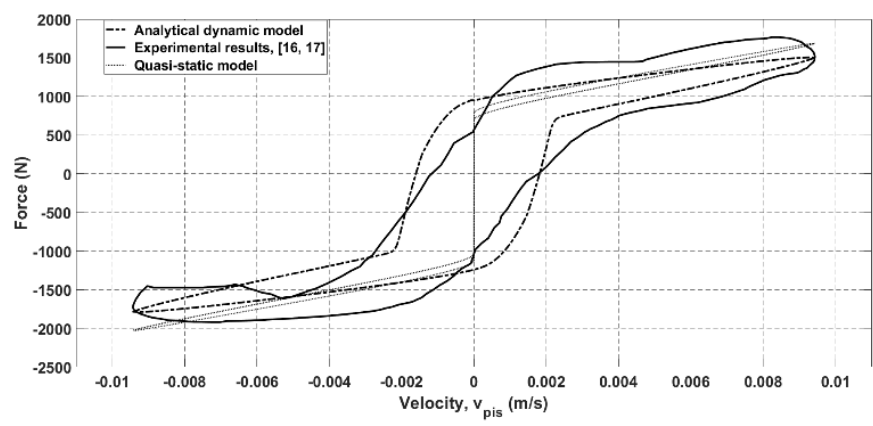

Fig. 11. Theoretical work diagram, $F-\dot{x}$, according to both the analytical dynamic and quasi-static models in comparison with the characteristic diagram deduced from the experimental measurements of the pressures in the chambers of the previously-tested damper in [17, 18].

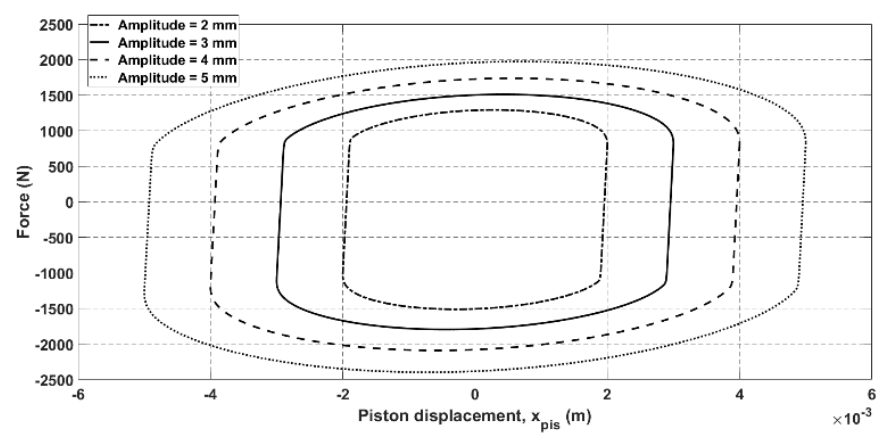

Fig. 12. Theoretical work diagrams, $F-\dot{x}$, of the previously-tested damper in $[17,18]$ at different amplitudes of the cyclic motion of the piston.

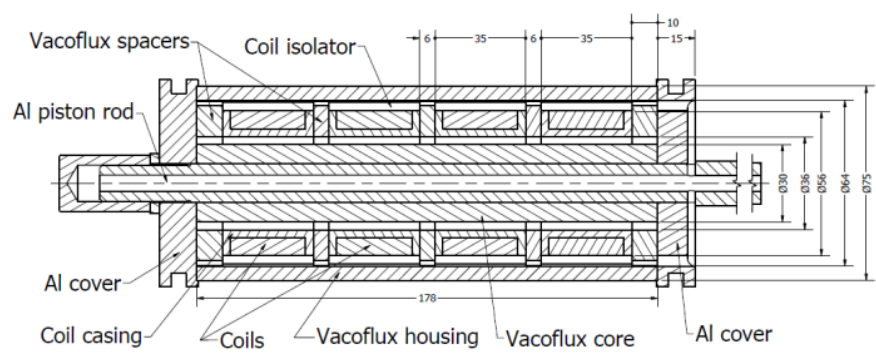

Fig. 13. Construction of the novel MR piston.

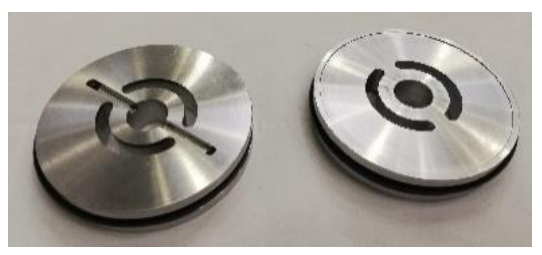

(a)

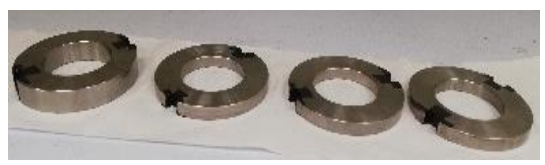

(b)

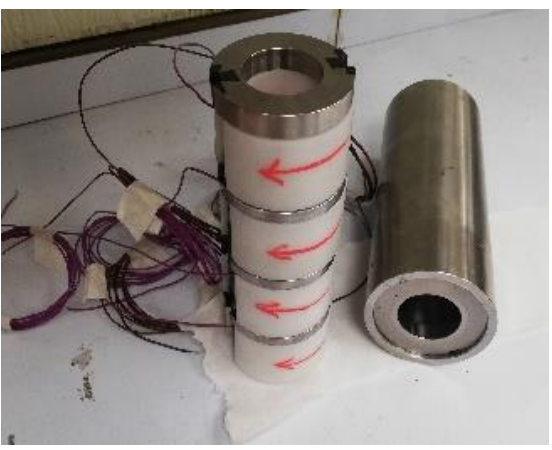

(c)

Fig. 14. Components of the magnetic circuit: (a) the aluminium covers, (b) the Vacoflux-50 spacers, and (c) the alignment of the coils and the spacers in the Vacoflux-50 housing.

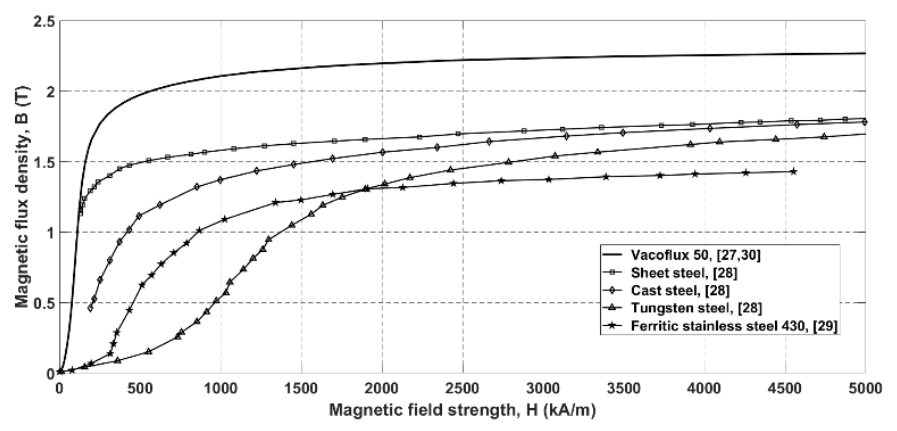

Fig. 15. Magnetic $B-H$ curves for different magnetic materials. 


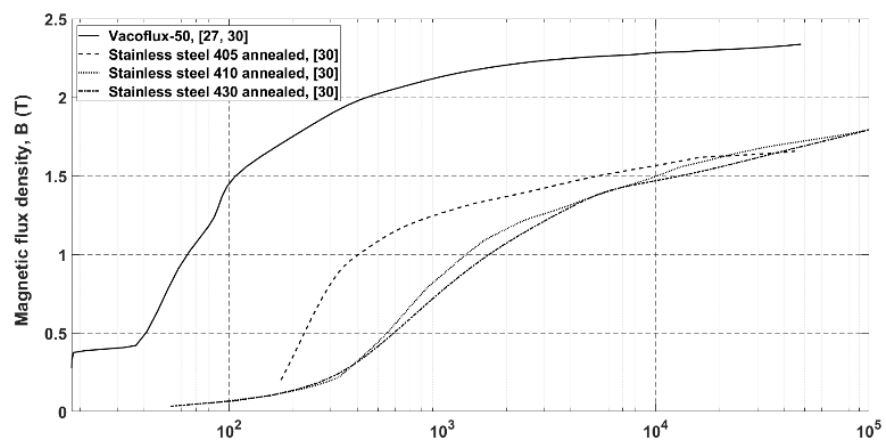

Fig. 16. Magnetic $B-H$ curves for different magnetic stainless steel alloys in comparison with Vacoflux-50, adapted from [30,33].

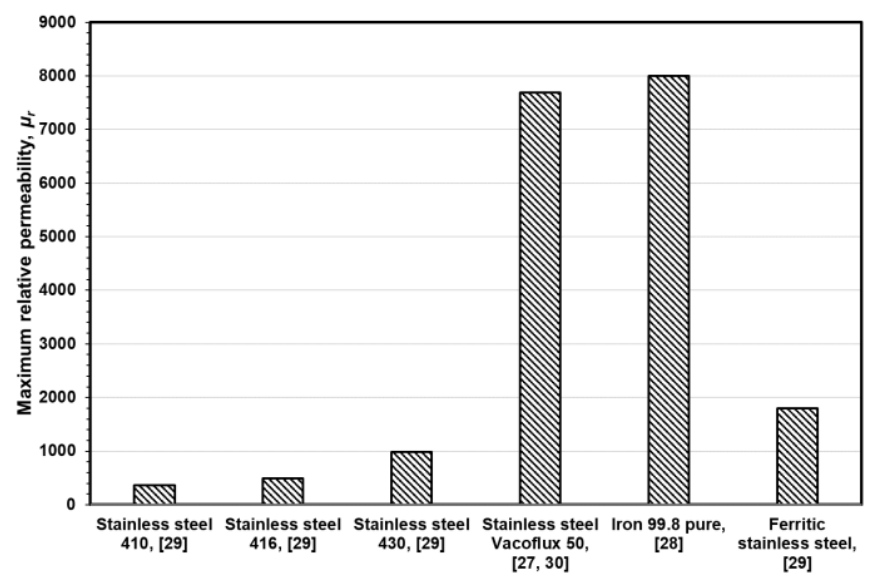

Fig. 17. Maximum values of permeability of different materials (at $20^{\circ} \mathrm{C}$ ).

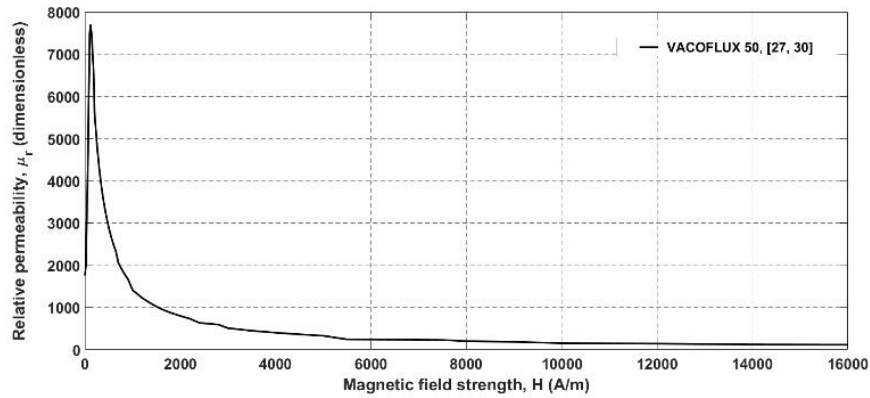

Fig. 18. The relative permeability of Vacoflux-50 at different magnetic field strengths $[30,33]$.

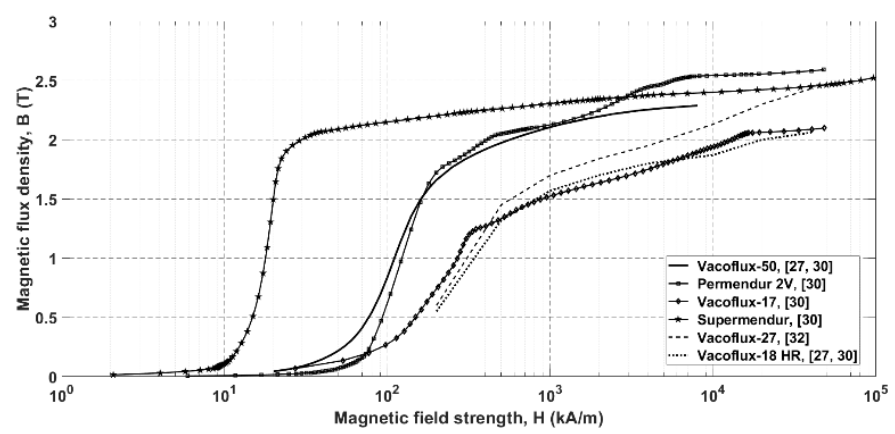

Fig. 19. Magnetic $B-H$ curves for different iron-cobalt-vanadium alloys in comparison with Vacoflux-50, adapted from [30, 33, 35].

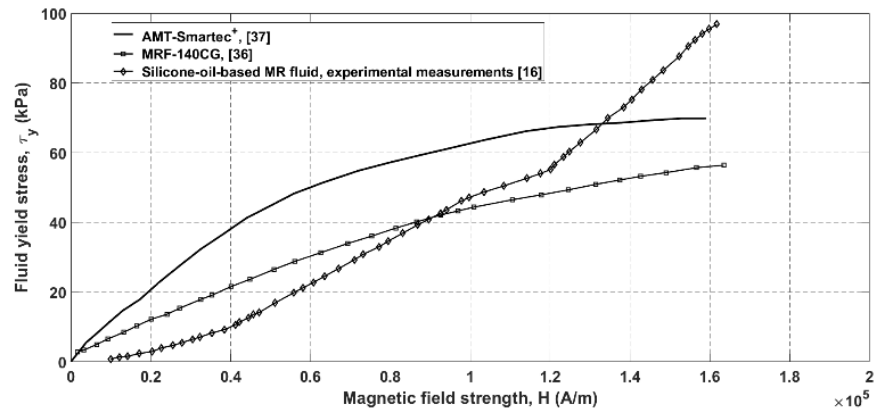

Fig. 20. Yield stress, $\tau_{y}$, against magnetic field strength, $H$, of different MR fluids, adapted from $[17,39,40]$.

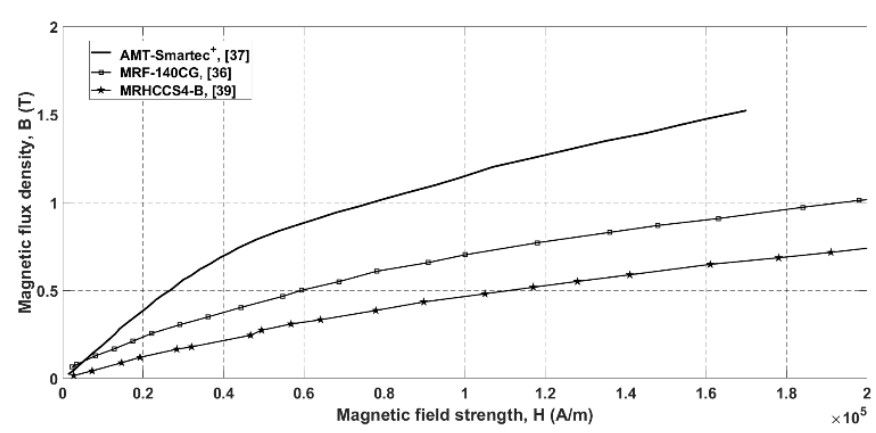

Fig. 21. Magnetic field density, $B$, against magnetic field strength, $H$, of different MR fluids, adapted from [39, 40, 42].

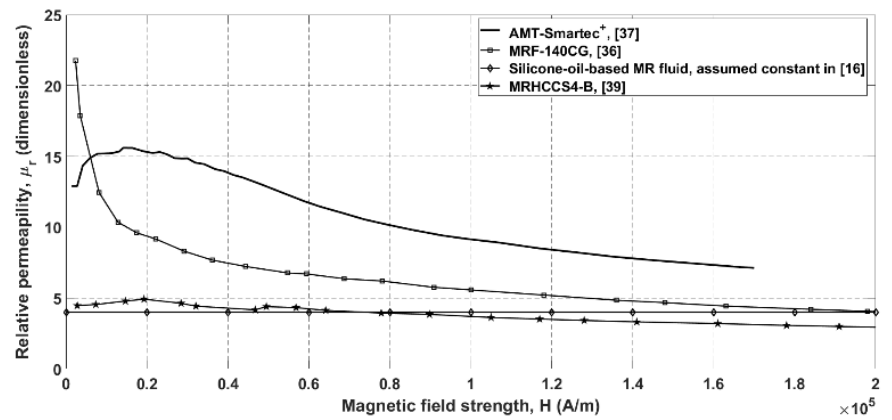

Fig. 22. Relative permeability, $\mu_{r}$, against magnetic field strength, $H$, of different MR fluids, adapted from [17, 39, 40, 42]. 

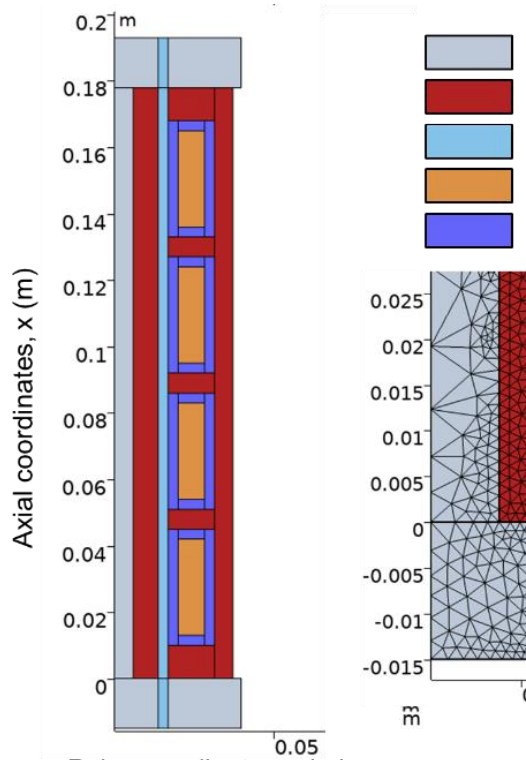

Aluminium

Vacoflux 50

MR fluid

Coil

Coil isolators

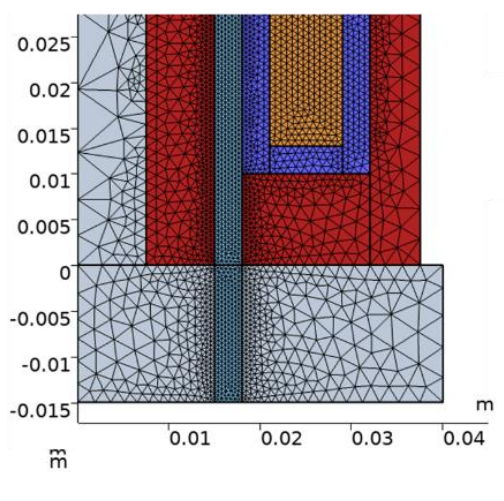

Polar coordinates, $r(\mathrm{~m})$

Fig. 23. The computational domain of the magnetic circuit.

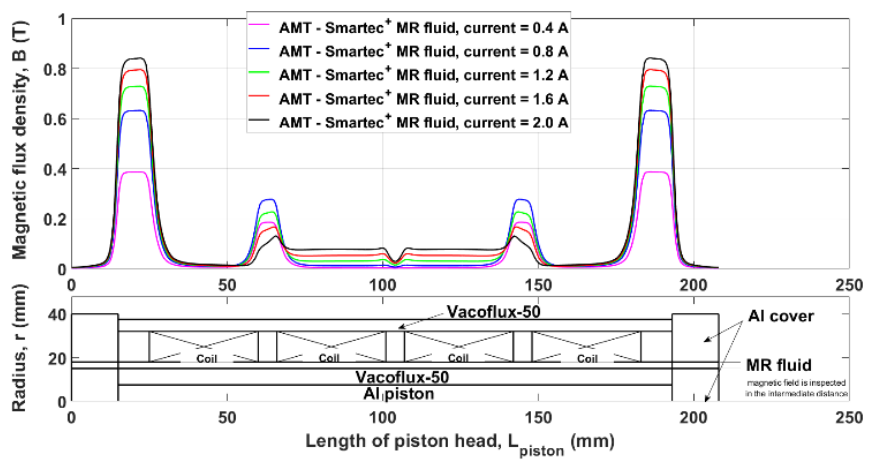

Fig. 24. Distribution of the magnetic flux density in the MR fluid region at different input currents to the coils, plotted on an intermediate line in the MR fluid region.

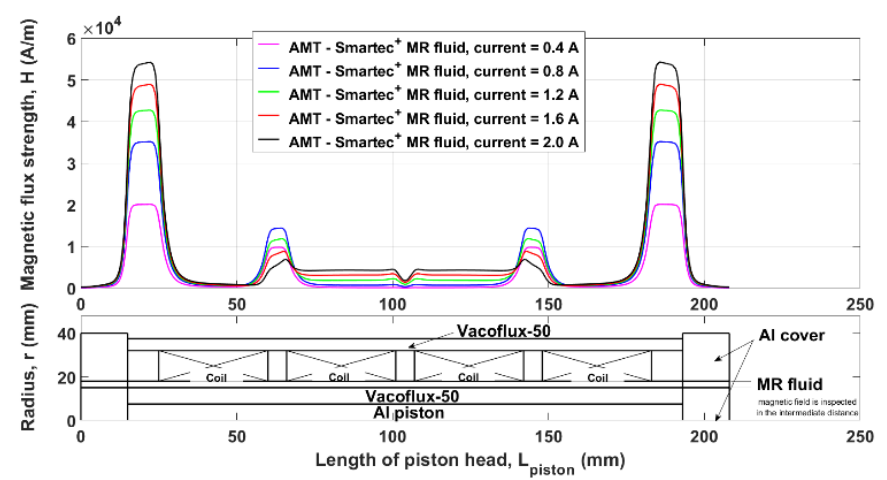

Fig. 25. Distribution of the magnetic flux strength in the MR fluid region at different input currents to the coils, plotted on an intermediate line in the MR fluid region.

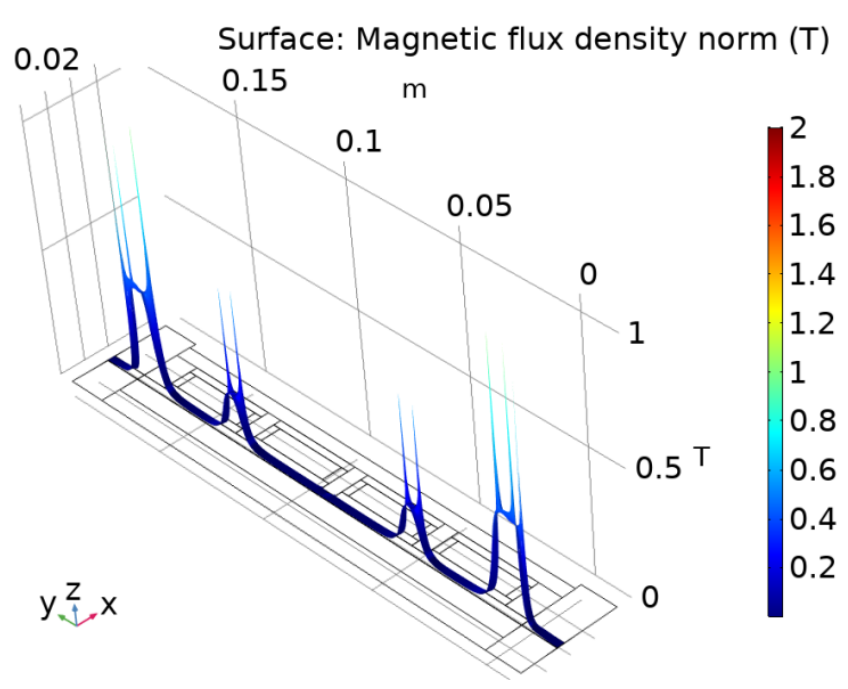

(a)

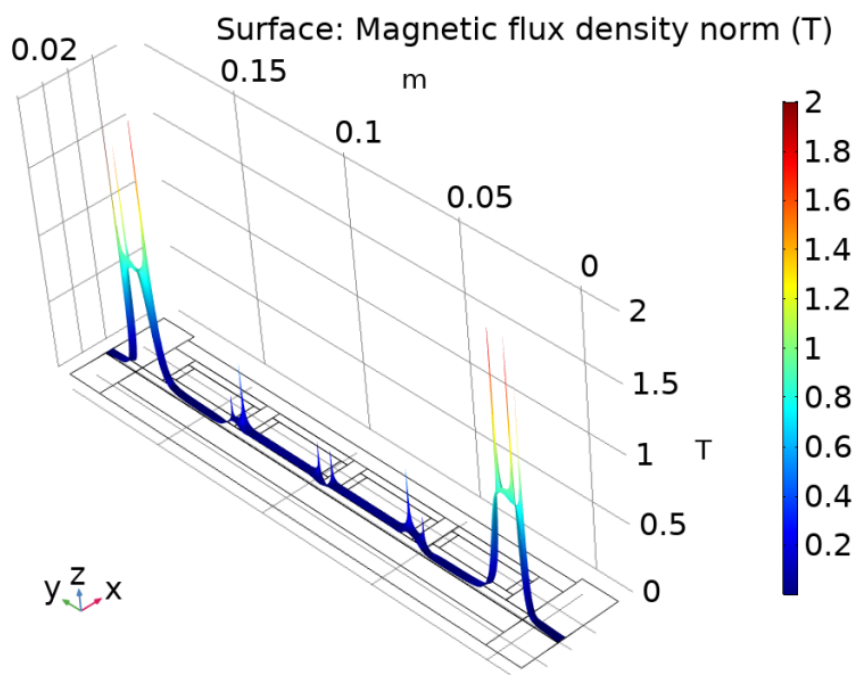

(b)

Fig. 26. Distribution of magnetic field density in the MR fluid region of the novel MR piston: (a) $I=0.4 \mathrm{~A}$, and (b) $I=2.0 \mathrm{~A}$.

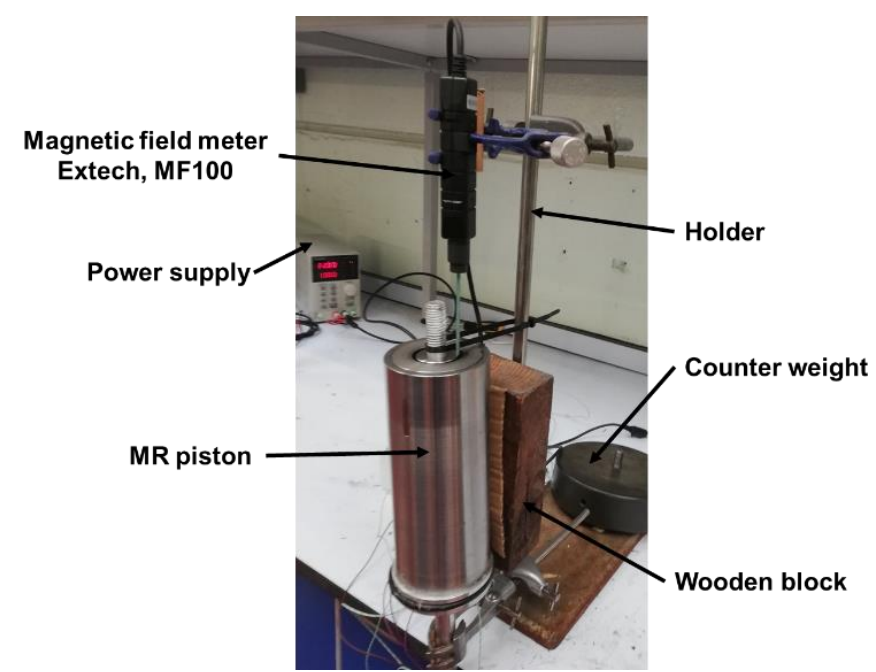

Fig. 27. Setup of the MR piston and the magnetic field meter to measure the steady-state magnetic field density in the MR fluid (air) region. 


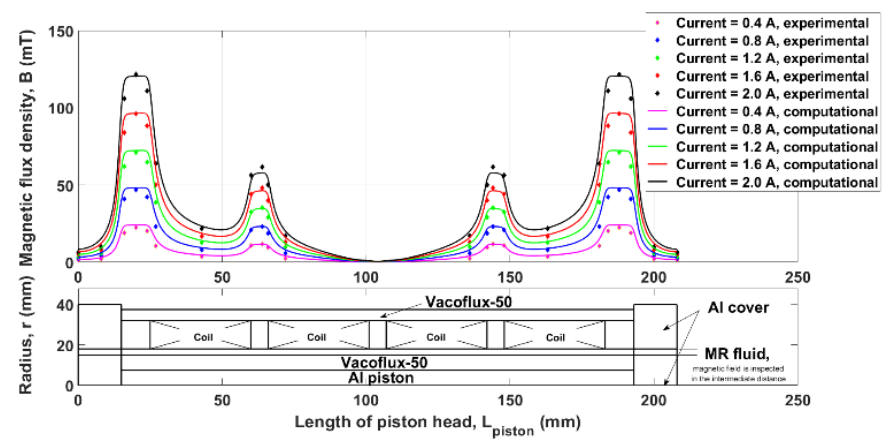

Fig. 28. Theoretical and experimental results of the distribution of the magnetic flux density in the MR fluid region (replaced with air), at different input currents. The values are plotted on an intermediate line in the MR fluid region.

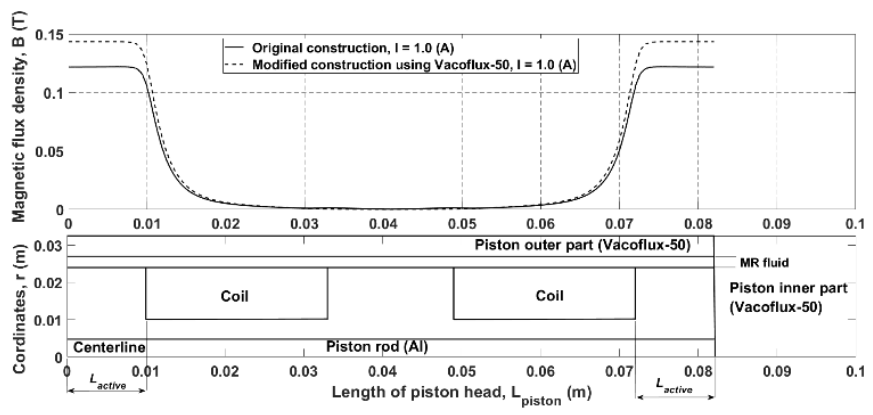

Fig. 29. Theoretical distribution of the magnetic flux density in the MR fluid region of the previously-tested MR piston in [1,14, 17], predicted by the current FE model due to the original design and the modified one by the employment of the Vacoflux-50 material.

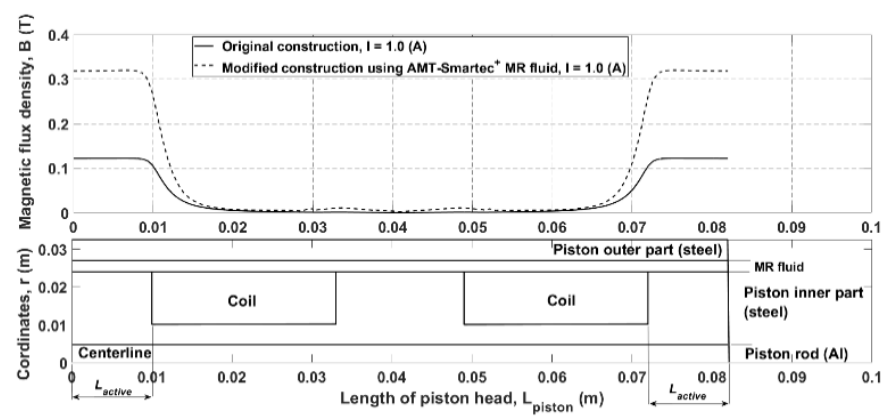

Fig. 30. Theoretical distribution of the magnetic flux density in the MR fluid region of the previously-tested MR piston in [1,14, 17], predicted by the current FE model due to the original design and the modified one by the employment of the AMT-Smartec ${ }^{+}$MR fluid.

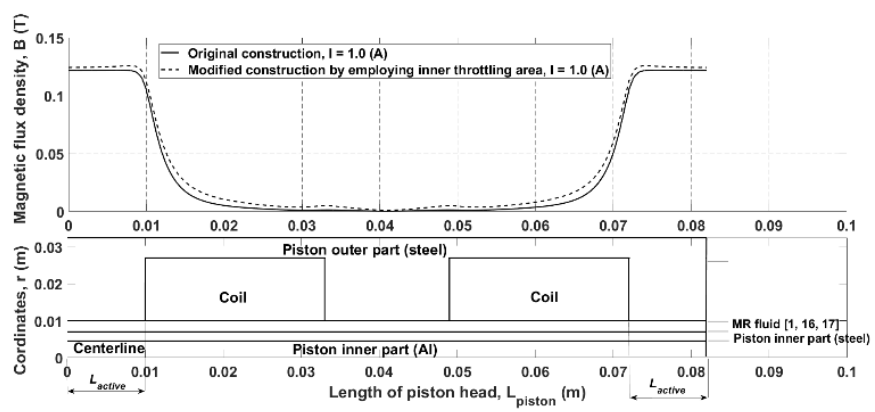

Fig. 31. Theoretical distribution of the magnetic flux density in the MR fluid region of the previously-tested MR piston in $[1,14,17]$, predicted by the current FE model due to the original design and the modified one by the insertion of the MR fluid region inside the coil bobbin.

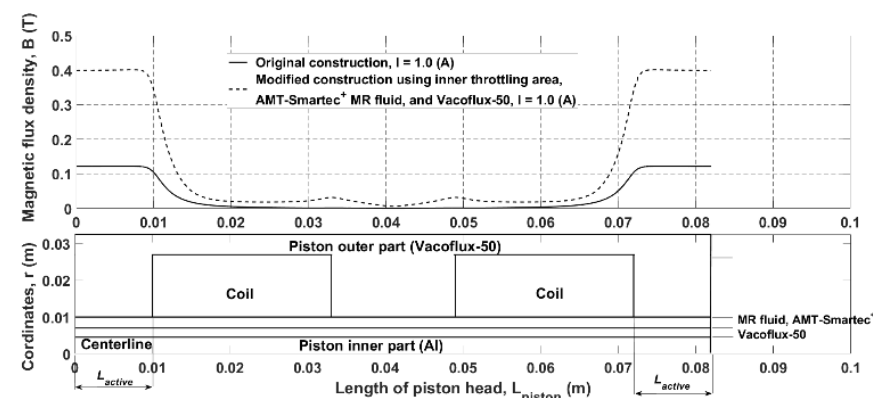

Fig. 32. Theoretical distribution of the magnetic flux density in the MR fluid region of the previously-tested MR piston in [1,14,17], predicted by the current FE model due to the original design and the modified one by the employing of Vacoflux-50 material, AMT-Smartec ${ }^{+}$MR fluid, and the insertion of the MR fluid region inside the coil bobbin.

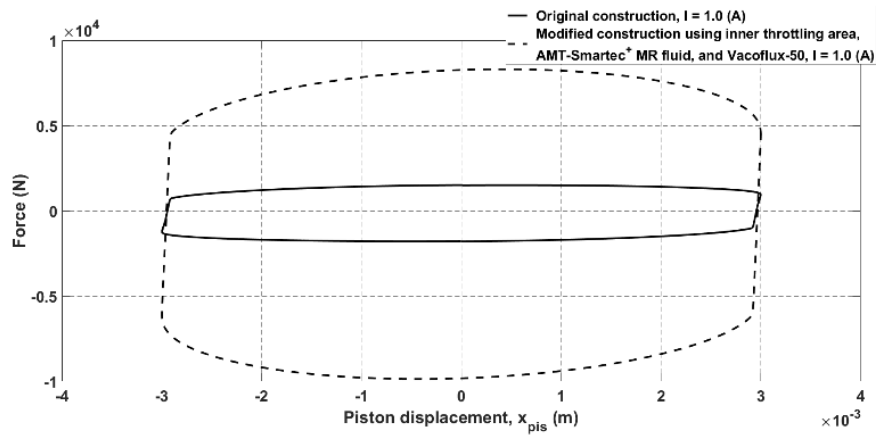

Fig. 33. Theoretical work diagrams predicted by the analytical dynamic model due to the original design presented in $[1,14,17]$, and the modified design by the employing of Vacoflux-50 material, AMT-Smartec ${ }^{+}$MR fluid, and the insertion of the MR fluid region inside the coil bobbin.

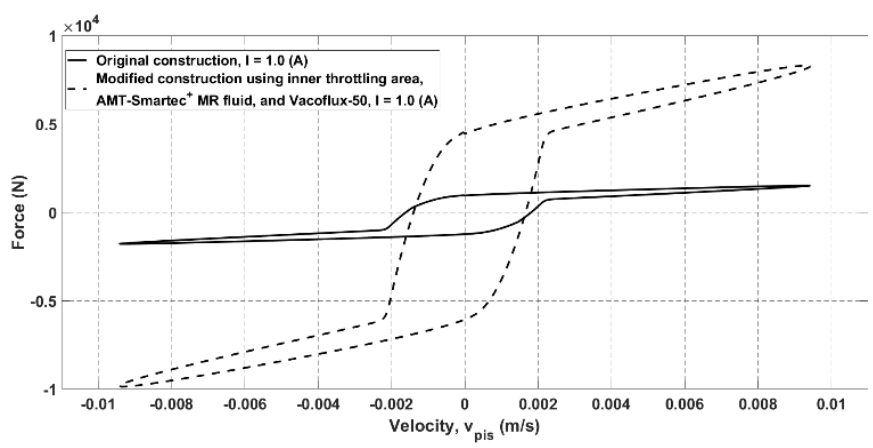

Fig. 34. Theoretical characteristic diagrams predicted by the analytical dynamic model due to the original design presented in $[1,14,17]$, and the modified design by the employing of Vacoflux-50 material, AMT-Smartec ${ }^{+}$MR fluid, and the insertion of the MR fluid region inside the coil bobbin. 


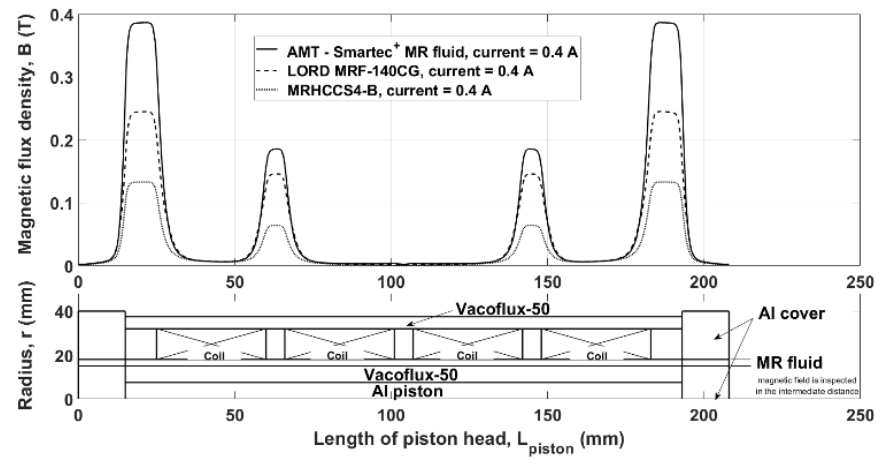

(a)

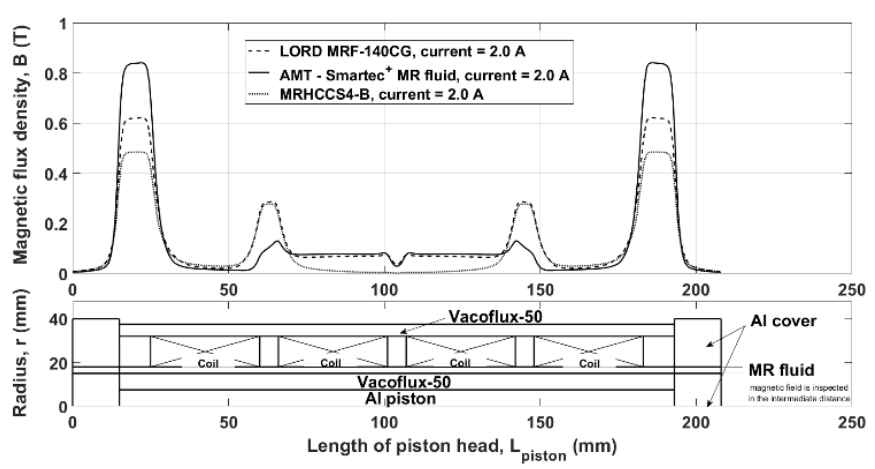

(b)

Fig. 35. Theoretical distribution of the magnetic flux density in the MR fluid region of the new damper, predicted by the current $\mathrm{FE}$ model due to the employment of different types of MR fluids: (a) at $I=0.4 \mathrm{~A}$, and (b) at $I=2.0$ A.

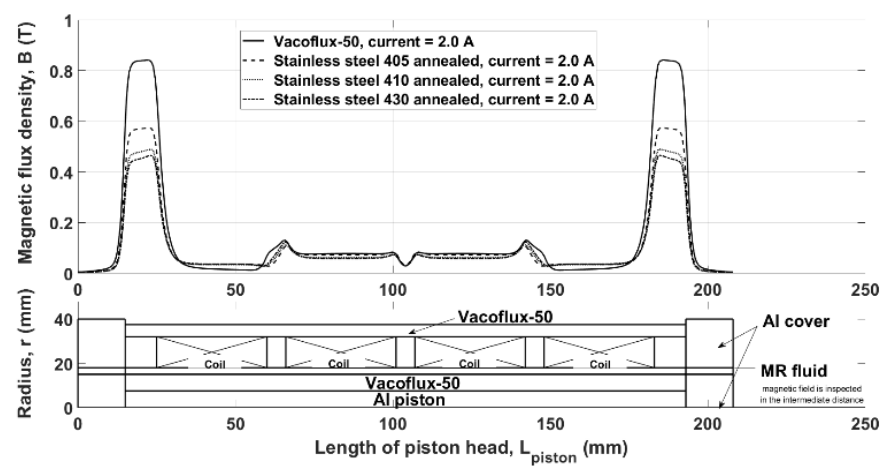

(a)

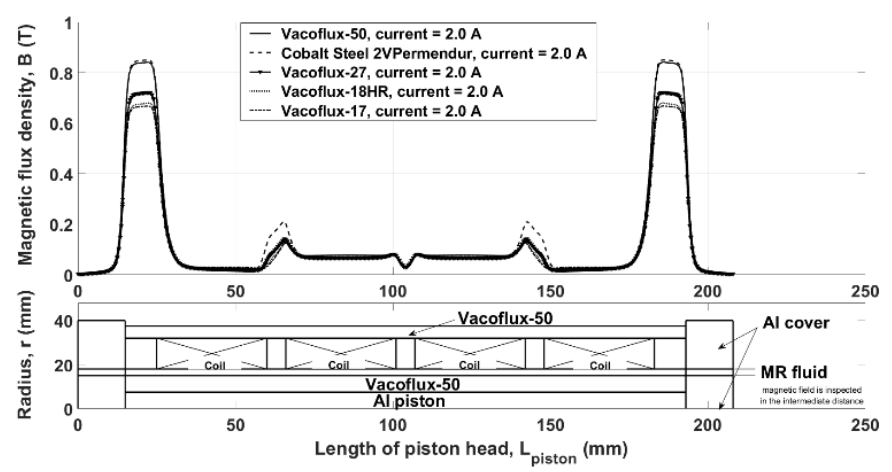

(b)

Fig. 36. Theoretical distribution of the magnetic flux density in the MR fluid region of the new damper at $I=2.0 \mathrm{~A}$, predicted by the current FE model due to the employment of different magnetic materials in the piston: (a) different magnetic stainless steel alloys, and (b) different iron-cobalt-vanadium alloys. 